\author{
Part of Journal of Research of the National Bureau of Standards, Volume 17, \\ October 1936
}

\title{
TEMPERATURE COMPENSATION OF MILLIVOLTMETERS
}

\author{
By Herbert B. Brooks
}

\begin{abstract}
The formulas hitherto published for the temperature compensation of millivoltmeters by the Swinburne method are inexact. Furthermore, their sole objective being temperature compensation, they are capable of a multiply infinite number of solutions for any given millivoltmeter "mechanism"; that is, the permanentmagnet structure and the moving eoil with its springs and pointer. Even if these formulas were free from error, their too-great generality imposes upon the instrument designer an impracticable amount of cut-and-try work to obtain a solution which takes care of other very necessary features besides temperature compensa-
\end{abstract} tion.

Merely as a matter of academic interest, this paper gives the exact solution of the problem in the very general form in which it has been attacked by previous writers. It then presents the most practically useful of a number of other exact solutions which have been derived for various combinations of the three requirements other than temperature compensation. This most useful solution gives the relations to be satisfied in a temperature-compensated millivoltmeter which is to have definite values of full-scale potential difference, total damping resistance, and resistance of the millivoltmeter. The use of this solution is illustrated by numerical examples based on an actual millivoltmeter mechanism. The new formulas which relate to temperature compensation with any two, and with any one of these other three important requirements are of lesser importance and are given in outline only.

Millivoltmeters are rarely used as such, their preponderant use being in connection with shunts for the measurement of current. The combination, in the usual manner, of a perfectly compensated millivoltmeter with a shunt of zero temperature coefficient of resistance forms an ammeter which is not perfectly compensated for temperature. When the current to be measured is large in comparison with the current taken by the millivoltmeter, the defect in compensation as an ammeter will be small or even inappreciable. When the current to be measured becomes of the same order of magnitude as the current taken by the millivoltmeter, the defect in compensation becomes important. This is true, whether the millivoltmeter be compensated by the method of simple series resistance or by the Swinburne method. This paper presents a theorem which makes it possible, with a millivoltmeter compensated by either method, to measure currents down to very small values with no impairment of the temperature compensation.

The use of a manganin multiplier to extend the range of a Swinburne-compensated millivoltmeter affects the compensation by an amount which increases asymptotically with the range toward a limiting value of about 0.2 percent per degree centigrade. A modification of the Swinburne network has long been used by a German manufacturer to give an additional compensated higher range (3 volts) with which manganin multipliers may be used without affecting the temperature compensation. No formulas relating to this modified network appear to have been published. Two formulas for this case are given, the first of which covers the case of a higher range having a random value of "ohms per volt" and the other having a desired round value of ohms per volt. Their use is illustrated by numerical examples relating to a multirange instrument actually constructed.

The use of the formulas for every compensated millivoltmeter manufactured would add undesirably to the cost. To reduce the cost of compensation to a minimum, simple experimental procedures for factory use are outlined by which 
millivoltmeters of a given type may be compensated rapidly and accurately if some previous experience has been had with the type in temperature compensation with the aid of the formulas.

\section{CONTENTS}

I. Introduction

II. Effects of a change in temperature

III. Methods for effecting temperature compensation

1. Compensation of a millivoltmeter used as such

2. Compensation of a millivoltmeter used with a shunt as an ammeter

3. Earlier formulas for the Swinburne method of temperature compensation.

IV. Exact formulas for the Swinburne method.

1. Current in the moving coil as a function of temperature..--

2. Case in which temperature compensation is the only requirement

3. Important requirements other than compensation

4. Compensation with specified full-scale potential difference, specified resistance of the millivoltmeter, and specified total damping resistance..........................

5. Numerical example of the preceding case

V. Use of a millivoltmeter with a shunt for measuring current.....-

1. Temperature compensation of a simple series-compensated millivoltmeter

2. Use of a shunt with a simple series-compensated millivoltmeter affects the temperature compensation ............

3. Temperature compensation of an ammeter consisting of a series-compensated millivoltmeter connected to a shunt.-

4. The preceding theorems concerning shunts apply also to Swinburne-compensated millivoltmeters_...............

VI. Multirange Swinburne-compensated instruments

1. Multirange millivoltmeters

2. Combined voltmeter-millivoltmeters ("volt-millivoltmeters")

3. Formula for locating the voltmeter tap point
4. Numerical examples of method of locating the voltmeter tap point.

5. Method for obtaining a round value of ohms per volt in the volt ranges

6. Numerical example of the method for obtaining a round value of ohms per volt

7. Importance of suitable choice of reference temperature and second temperature for compensation over a wide range of temperature.

VII. Compensation of a millivoltmeter when some quantities are specified and the others may be chosen arbitrarily

1. Compensation with specified full-scale potential difference--

2. Compensation with specified resistance of the millivoltmeter . . . . . .

3. Compensation with specified total damping resistance...-

4. Compensation with specified full-scale potential difference and specified resistance of the millivoltmeter............

5. Compensation with specified full-scale potential difference and specified total damping resistance.............

6. Compensation with specified resistance of the millivoltmeter and specified total damping resistance ............

VIII. Experimental procedures for routine compensation of instruments of a given type

1. Necessity for and preparations for the experimental procedures

2. Experimental procedure for specified full-scale potential difference and specified resistance of the millivoltmeter...

3. Experimental procedure for specified full-scale potential difference and specified total damping resistance........

Page

499

499

500

500

501

502

504

504

506

508

508

512

514

514

515

515

520

521

521

523

524

527

530

536

542

544

544

544

544

545

545

546

547

547

549

551 
VIII. Experimental procedures for routine compensation of instruments of a given type-Continued.

4. Experimental procedure for specified full-scale potential difference, specified resistance of the millivoltmeter, and specified total damping resistance of an instrument of normal strength of magnet.........

5. Experimental procedure for locating the voltmeter tap point

6. Experimental procedure for determining the effect on the compensation of manufacturing variations of millivoltmeter constants from their average values.............

\section{INTRODUCTION}

A millivoltmeter is a voltmeter of such low range that the millivolt is the convenient unit for use in marking its scale. Millivoltmeters for direct current are usually made with full-scale values up to 750 millivolts. Similar instruments with full-scale values of 1 volt and above are usually called voltmeters and have their scales marked in volts. Millivoltmeters are used to only a limited extent for the measurement of potential differences, such as those in bolted contacts or switch contacts, or between adjacent commutator bars in the testing of armatures. For such measurements high accuracy is not required, consequently the effect of change of ambient temperature on the indications is usually not important.

By far the most important use of the millivoltmeter, however, is in connection with shunts for the measurement of currents. The range of such measurements is very wide, namely, from a small fraction of an ampere up to thousands of amperes. When a millivoltmeter is so used with a shunt, the propriety of calling it a "millivoltmeter" may be challenged, especially when its scale is marked in amperes. In such a case, the combination of millivoltmeter, leads, and shunt is effectively an ammeter. If the shunt (or a group of shunts) is built into the instrument and the scale is marked in amperes, the combination is always called an ammeter. However, when the shunts are external accessories, and the scale is marked in millivolts, the apparatus is usually called a "millivoltmeter with external shunts."

\section{EFFECTS OF A CHANGE IN TEMPERATURE}

For many measurements of direct current it is important that the accuracy shall not be appreciably affected by ordinary variations of the ambient temperature. The power loss in the windings of a millivoltmeter is so small that the temperature rise from this source is negligible. The practical requirement that a millivoltmeter shall give full-scale deflection for a relatively small potential difference between its terminals tends toward a construction which gives a relatively large change in the indication of the instrument as the ambient temperature varies. The net effect on the indication of a change in ambient temperature is the resultant of a number of changes, some of which tend to annul each other, and others, such as those caused by change of dimensions of the parts of the instrument, produce inappreciable effects on the indication.

In a permanent-magnet moving-coil instrument an increase of temperature of $1^{\circ} \mathrm{C}$ reduces the strength of the spring approximately 0.04 percent and reduces the magnetic flux density in the air gap about 0.02 percent. The weakening of the spring tends to increase the 
deflection for a given current in the coil, and the lowering of the flux density tends to decrease the deflection; the net effect, in the average instrument, of a change of $1^{\circ} \mathrm{C}$ is thus to increase the deflection about 0.02 percent. The moving coil is usually of copper, sometimes of aluminum, and in either case its resistance increases about 0.4 percent for an increase of temperature of $1^{\circ} \mathrm{C}$. If the small voltage to be measured could be applied directly to the coil, the reading of the instrument would thus decrease by $0.40-0.02=0.38$ percent for a temperature rise of $1^{\circ} \mathrm{C}$. This high value of temperature coefficient of the indication would be prohibitive for most purposes. With the facilities now available it is a simple matter to effect "temperature compensation" in a voltmeter of any range from a few volts up to any desired value. In a millivoltmeter, however, the desirability of minimizing the full-scale potential difference at the instrument terminals has made the problem somewhat difficult.

\section{METHODS FOR EFFECTING TEMPERATURE COMPENSATION}

\section{COMPENSATION OF A MILLIVOLTMETER USED AS SUCH}

It is possible to effect complete compensation of the average millivoltmeter by adding to the copper coil a series resistor of manganin ${ }^{1}$ wire having a resistance of about 19 times that of the copper coil. This reduces the temperature coefficient of resistance of the instrument to one-twentieth of that of copper, and with a constant potential difference at the instrument terminals the decrease of current through the instrument as the temperature increases just balances the tendency, in the average instrument, toward increased deflection because of changes in the magnetic field and in the strength of the springs. As compared with the more complicated method of compensation which forms the principal subject of study in this paper, this method of compensation merely by the use of series resistance would be preferable because of its simplicity if it were not for one serious disadvantage, namely, the relatively high value of full-scale potential difference which is necessary if the instrument mechanism is to be sufficiently strong and the time for the pointer to come to rest is not to be too long. If these two requirements are to be satisfied, it is necessary to have a full-scale potential difference of say 100 to 200 millivolts. In switchboard instruments, and in portable instruments of medium grade for purposes not requiring the highest accuracy, the full-scale potential difference may be kept down by using only enough series resistance of manganin wire to get a partial compensation adequate for the purpose. Shunts having a drop of 50 millivolts with rated current may be used with such instruments. For portable instruments of precision grade a relatively high degree of temperature compensation is necessary, and when instruments of this grade, with a suitable relation between the full-scale torque and the weight of the moving element, are compensated merely by the use of series resistance, the full-scale potential difference of the instrument is too large to permit the use of 50 -millivolt shunts.

Another method of compensating millivoltmeters avoids the difficulty of an excessive value of potential difference for full-scale deflec-

\footnotetext{
"The word "manganin" is used in this paper as a brief substitute for the inconveniently long expression "material of negligibly small temperature coefficient of resistance."
} 
tion. It is based on the early work of Swinburne ${ }^{2}$ in the temperature compensation of electrical instruments, and although he did not apply the method specifically to millivoltmeters it will be called the Swinburne method in this paper. It is illustrated by the diagram of figure 1. A manganin coil $a^{\prime \prime}$ is connected in series with the moving coil $a^{\prime}$; a coil $b$ of relatively large temperature coefficient $\beta$ is connected in parallel with the two, and a coil $c$, usually and preferably of manganin wire, is connected as shown. The symbols $a^{\prime}, a^{\prime \prime}, b$, and $c$ denote the various coils and also their resistances without reference to any particular temperature. The symbol $a^{\prime}$ refers to the moving coil and its springs and the sum of $a^{\prime}$ and $a^{\prime \prime}$ is denoted by $a$. The temperature coefficient $\alpha$ of the branch $a$ is less than that of the copper or aluminum wire of the moving coil, partly because the series resistor $a^{\prime \prime}$ is made wholly or partly of manganin, and also because the temperature coefficient of resistance of the alloy springs is less than that of the wire of the coil. If the proper relations exist between the resistances and the temperature coefficients of the three branches $a, b$, and $c$ of this network, the millivoltmeter will give the same indication, for a given applied voltage, at a chosen reference temperature and at a chosen other temperature. Between these temperatures the indication will go through a maximum value slightly greater than the indication at the chosen temperatures. If the values of resistance and temperature coefficient are properly chosen, the potential difference at the millivoltmeter terminals for full-scale deflection may be made less than 5 times the potential difference at the ends of the moving coil itself, as contrasted with 20 times for the simple series method of compensation. The Swinburne method makes it possible to obtain accurate temperature compensation in millivoltmeters of good torque-weight characteristic requiring only 50 millivolts for full-scale deflection. This advantage is secured at the cost of slightly greater complexity of the millivoltmeter network. A special limitation of the Swinburne-compensated millivoltmeter is that it has a relatively large temperature error if it be used either as an unshunted milliammeter or with a multiplier to increase its range as a millivoltmeter.

\section{COMPENSATION OF A MILLIVOLTMETER USED WITH A SHUNT AS AN AMMETER}

When a current is to be measured with a millivoltmeter connected to an external shunt it is necessary to assume that the shunt and the millivoltmeter may be at appreciably different temperatures because of either difference of environment or the temperature rise of the shunt under load. It follows that the resistance of the external shunt should not vary appreciably with temperature. If the shunt is mounted within the millivoltmeter and in sufficiently intimate thermal proximity to the moving coil, and the current to be measured is so small that the shunt and the moving coil have closely equal temperatures under all conditions, it is not necessary either that the shunt should have a zero temperature coefficient or that the millivoltmeter should be temperature compensated. As an extreme case of this kind, a millivoltmeter having a copper moving coil may have

\footnotetext{
2 Electrician (London) 19, 405 (1887); Elec. World 10, 169 (1887); British patent no. 3942, issued Dec. 19.
} 1885 . 
an internal copper shunt of small current rating (and hence small rise of temperature under load) and the combination will be nearly free from temperature error.

It will be shown later in this paper that in general the use of a current shunt with a compensated millivoltmeter affects the temperature compensation of the combination, used as an ammeter; that this effect is greater, the greater the resistance of the shunt, that is, the smaller the current to be measured; and that a simple procedure may be used to maintain compensation down to values of current so low as to be comparable with the current in the moving coil of the millivoltmeter.

\section{EARLIER FORMULAS FOR THE SWINBURNE METHOD OF TEMPERATURE COMPENSATION}

Although it was announced in general terms in 1885, the underlying principle of the Swinburne method seems not to have been put into mathematical form until twenty years later. The first such treatment which the author has found is that of Hallo and Land, ${ }^{3}$ who derived a simple but incomplete formula which in the symbols of this paper (see fig. 1) is

$$
c=b \cdot \frac{\alpha}{\beta-\alpha}
$$

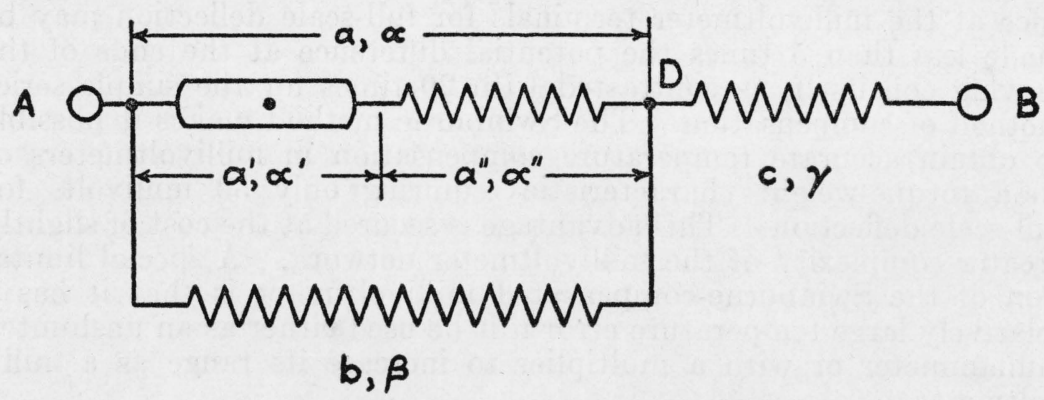

FigURE 1.-Diagrammatic plan of circuits of a Swinburne-compensated millivoltmeter.

The moving coil of resistance $a^{\prime}$ and temperature coefficient of resistance $\alpha^{\prime}$ is in series with a manganin coil $a^{\prime \prime}$. The temperature coefficient $\boldsymbol{\beta}$ of coil $b$ is relatively large, $\gamma$, that of $c$, is relatively small, preferably zero. The degree of temperature compensation depends upon the relations between $a, b$, and $c$ and their temperature coefficients.

In the derivation of this formula Hallo and Land failed to consider the fact that a change in the temperature of the magnet and the springs changes the value of the current in the moving coil for a given deflection.

A more accurate solution, obtained by Heinrich and Bercovitz, ${ }^{4}$ was given by them in the form

$$
c=b \cdot \frac{\alpha}{\beta-\alpha}
$$

\footnotetext{
3 H. S. Hallo and H. W. Land, Elektrische und Magnetische Messungen und Messinstrumente, p. 259, Berlin (1906). This book is stated to be a free revision and amplification of the Dutch book by G. W. van Swaay, entitled Magnetische en Elektrische Metingen, Delft (1902). A careful search through this latter book revealed no discussion of the $\mathbf{S}$ winburne method of compensation.

'Heinke's Handbuch der Elektrotechnik, Bd. 2, Abt. 5, p. 34, (1907).
} 
The symbol $\alpha$ was used by them to denote a pseudo temperature coefficient of resistance, and is defined by them in words of which the following is a translation:

In this (equation) the temperature coefficient $a$ of the moving coil represents the combined coefficient of the variation of the resistance and of the instrument coefficient of the system.

The term "instrument coefficient" used by these writers is not exactly defined by them but apparently may be taken to denote the temperature coefficient of the deflection with a constant current in the moving coil. This latter coefficient should be brought into the analysis, but not in the manner adopted by Heinrich and Bercovitz. The use of such a composite temperature coefficient in equations dealing with the distribution of current in the branches of a network leads necessarily to an inaccurate result. The formula of Heinrich and Bercovitz, however, contains the term $1+\beta t$, overlooked by Hallo and Land. This term shows that if the millivoltmeter is initially adjusted at some reference temperature it can be exactly compensated for only one other temperature $t^{\circ}$ different from the reference temperature. Heinrich and Bercovitz did not indicate the manner in which the composite temperature coefficient $\alpha$ was to be experimentally determined.

A few years later, Kollert ${ }^{5}$ published the results of what appears to be the first detailed study of the properties and limitations of the Swinburne method. He derived an equation for compensation which agrees in form with that of Heinrich and Bercovitz, eq 2. Like them, he used the symbol $\alpha$ to denote a composite of the temperature coefficient of resistance of the moving-coil branch $a$ (fig. 1) and the temperature coefficient of the deflection with a given current in the moving coil. Kollert indicated the procedure by which the value of this composite temperature coefficient was to be experimentally determined. As in the case of Heinrich and Bercovitz, the use of such a pseudo temperature coefficient could not lead to an exact solution. The true temperature coefficients of resistance of all the branches of a network, and no others, must be used in an analysis to determine the currents in the various branches, and the "instrument coefficient" of Heinrich and Bercovitz, or its equivalent, must be introduced properly as affecting the deflection for a given current but not the distribution of current in the network.

Kollert attacked another phase of the problem, overlooked by previous writers, which may be stated as follows: how should the values of $\alpha$ and $b$ be chosen in order to obtain temperature compensation with a minimum value of $e$, the full-scale difference of potential at the millivoltmeter terminals, and how large will be this value? His analysis shows that $e$ becomes smaller as $b$ is reduced and reaches a minimum for the impractical case of $b=0$, for which $c$ also must be zero. Too low a value of $b$ gives an undesirably large value of the current required by the millivoltmeter for full-scale deflection. Too large a value of $b$, on the other hand, requires too large a value of $e$. Kollert's formula, like its predecessors, has the practical defect of offering a multiply infinite number of solutions, for all of which temperature compensation would be possible (if it were not for the inexactness of the formulas), and from which the instrument designer would have to choose by the cut-and-try method. None of these

\footnotetext{
s Elektrotech Z. 31, 1219 (1910).
} 
earlier formulas contains anything to guide the designer to the particular solution (or solutions) which provide compensation and also satisfy other requirements to be met.

Campbell, ${ }^{6}$ in 1905 , described a means for obtaining temperature compensation in direct-current ammeters. He used a Wheatstone bridge in which two diagonally opposite arms had a large temperature coefficient of resistance and the other two had a negligible temperature coefficient. The moving coil of the millivoltmeter mechanism formed one diagonal of the bridge and the ammeter shunt and a pair of connecting leads formed the other diagonal. If the resistance of one of the arms having a high temperature coefficient is made infinite the Campbell network reduces to that of Swinburne. It appears probable that little difference in performance of the two types of network is to be expected. Because of the much greater complexity of the equations for the Campbell network and the somewhat greater complexity in construction which it entails, the author feels that the time which would be required for a complete comparative analysis of the two networks would not be justified.

It is possible to obtain temperature compensation by the use of a magnetic shunt made of a nickel-steel alloy or of one of the more recent copper-nickel-iron alloys, in which the permeability decreases with increasing temperature. ${ }^{7}$ This method does not seem to have found commercial acceptance as yet.

\section{EXACT FORMULAS FOR THE SWINBURNE METHOD}

\section{CURRENT IN THE MOVING COIL AS A FUNCTION OF TEMPERATURE}

Referring to figure 2, the straight line st represents the constant deflection of a perfectly compensated millivoltmeter as the temperature is varied while the difference of potential between the millivoltmeter terminals is kept constant. The straight line op shows the manner in which the current $i$ in the moving coil must vary with the temperature in order to produce this result. ${ }^{8}$ Such a variation of current is readily obtained in a millivoltmeter which is compensated by the use of a manganin series resistor only, the proportion of manganin to copper ${ }^{9}$ being such as to make the temperature coefficient of resistance $d r / d t$ equal to $d i / d t$, the slope of the line op. It will be shown that such a result cannot be obtained by the Swinburne method, with which the current through the moving coil and the deflection for a constant difference of potential between the millivoltmeter termi-

6 J. Inst. Elec. Engrs. 35, 197 (1905).

7 Trans. Am. Inst. Elec. Engrs. 44, 275 (1925); 49, 949 (1930).

8 The slope of op is exaggerated for clearness. Actually dildt may be between 0 and 0.0003 . The reason why the current must decrease with increasing temperature, in order to maintain a constant defiection for a constant difference of potential, is to be found in the effects of temperature change upon the magnetic flux density and the strength of the springs. These effects have been discussed in section II, page 499 .

o Strictly speaking, this should be "the proportion of manganin to the copper equivalent." The alloy springs used in electrical measuring instruments have a temperature coefficient intermediate between those of copper and of manganin. The copper (or aluminum) moving coil and the springs are equivalent, so far as variation of resistance with temperature is concerned, to a copper coil of somewhat greater resistance than the actual coil, in series with a manganin coil having a resistance somewhat less than that of the springs, the sum of these two equivalent resistances being equal, at any temperature, to the sum of the resistances of the coil and the springs. The resistance of this equivalent copper coil may be called, for brevity, the "copper equivalent." 
nals will have forms such as $o^{\prime} p^{\prime}$ and $s^{\prime} t^{\prime}$, respectively. ${ }^{10}$ With the Swinburne method, therefore, the constants of the network are chosen to make the curve $o^{\prime} p^{\prime}$ cut the curve op at points corresponding to chosen temperatures $t_{1}$ and $t_{2}$, at which the curve $s^{\prime} t^{\prime}$ will accordingly cut the curve st. The reason for this departure of $o^{\prime} p^{\prime}$ from a straight line will appear from the expression for the current $i$ in the moving coil produced by a difference of potential $e$ between the milli-

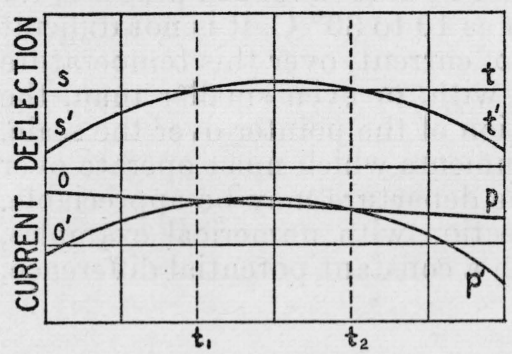

TEMPERATURE

Figure 2.-Curve st represents the constant deflection produced by a current in the moving coil which decreases slightly with increasing temperature as indicated by the sloping line op.

Curve $s^{\prime} t^{\prime}$ shows the nonlinear deflection produced by a current in the moving coil which varies with the temperature as represented by the line $o^{\prime} p^{\prime}$. A curvature of this general form in the current-temperature curve and in the deflectiontemperature curve characterizes the Swinburne method of compensation.

same effect in determining the curent in the branch $b$ produces by diverting a part of the total current around the branch $a$. The equivalent resistance $q$ satisfies the relation

$$
q=\frac{e}{i}
$$

If $e$ be kept constant while the temperature is increased the resistance $a$ will increase linearly with the temperature; $c$ will preferably be invariable with temperature, or if necessary, will increase linearly at a very small rate. The term $a c / b$ in the expression for the equivalent resistance is the one which causes the variation of $i$ to be nonlinear. Since $c$ is either invariable or varies linearly, it may be ignored and attention may be given to the manner of variation of its coefficient $a / b$. The temperature coefficients of $a$ and $b$ being denoted by $\alpha$ and $\beta$, the ratio $a . b$ after an increase of $t^{\circ}$ in the temperature may be written in the form

$$
\frac{a(1+\alpha t)}{b(1+\beta t)}=\frac{a}{b}\left[1-(\beta-\alpha) t+\left(\beta^{2}-\alpha \beta\right) t^{2} \ldots . . .\right]
$$

${ }_{10}$ The curvature of the lines $o^{\prime} p^{\prime}$ and $s^{\prime} t^{\prime}$, like the slope of the line op, is much exaggerated in the figure. $89799-36-2$ 
which shows that when $\beta>\alpha$ (a necessary condition for compensation) the ratio $a / b$ varies in an approximately parabolic manner with temperature. The total current taken by the millivoltmeter does likewise, and because the resistance of each of the branches $a$ and $b$ varies linearly with temperature, it follows that the current in each of these branches varies nonlinearly with temperature. Lest the impression should be given, however, that this curvature in the current-temperature curve is a serious matter, it should be stated that in practice, for moderate ranges of temperature such as 10 to $30^{\circ} \mathrm{C}$, it is not difficult to keep the departure from linearity of current, over this temperature range, so small as to be comparable with, or even smaller than, the limit of precision of reading the position of the pointer over the scale. When the method is applied to instruments which must operate over much greater temperature ranges, the departure may be appreciable. Curves will be given later, in connection with numerical examples, showing the change of deflection, with a constant potential difference, over a range of temperature.

\section{CASE IN WHICH TEMPERATURE COMPENSATION IS THE ONLY REQUIREMENT}

The exact solution of this most general but least useful case of the Swinburne method will now be given, chiefly for comparison with the results of earlier attempts at a solution. It is required to find a relation between the resistances and the temperature coefficients of resistance of the three branches of the Swinburne network (fig. 1) such that the current through the moving coil produced by a constant potential difference between the terminals $A$ and $B$ shall vary with temperature in the manner of $o^{\prime} p^{\prime}$, figure 2, and cut the ideal line $o p$ at points corresponding to selected temperatures $t_{1}$ and $t_{2}$. $t_{1}$ is

Referring to eq 3 , the current $i_{1}$ in the moving coil at temperature

$$
i_{1}=\frac{e}{a_{1}+c_{1}+\frac{a_{1} c_{1}}{b_{1}}}
$$

This temperature will be regarded as the reference temperature at which the millivoltmeter is adjusted to read correctly. The temperature coefficients ${ }^{11} \alpha, \beta$, and $\gamma$ will be based on the reference values of resistance $a_{1}, b_{1}$, and $c_{1}$, so that at the higher temperature $t_{2}$

$$
\begin{aligned}
& a_{2}=a_{1}\left[1+\alpha\left(t_{2}-t_{1}\right)\right] \\
& b_{2}=b_{1}\left[1+\beta\left(t_{2}-t_{1}\right)\right] \\
& c_{2}=c_{1}\left[1+\gamma\left(t_{2}-t_{1}\right)\right]
\end{aligned}
$$

If these values be substituted in eq 6 in place of the values which relate to temperature $t_{1}$, the current in the branch $a$ (and hence in the moving coil) at temperature $t_{2}$ is

$$
i_{2}=\frac{e}{a_{1}\left[1+\alpha\left(t_{2}-t_{1}\right)\right]+c_{1}\left[1+\gamma\left(t_{2}-t_{1}\right)\right]+\frac{a_{1}\left[1+\alpha\left(t_{2}-t_{1}\right)\right] c_{1}\left[1+\gamma\left(t_{2}-t_{1}\right)\right]}{b_{1}\left[1+\beta\left(t_{2}-t_{1}\right)\right]}}
$$

\footnotetext{
11 In previous treatments of the subject, to simplify the problem, the branch $c$ has always been assumed to have a temperature coefficient of zero. It will be shown later that $\gamma$ cannot always be made equal to zero.
} 
This current must be smaller than $i_{1}$ to keep the deflection unchanged, and the relation to be satisfied is

$$
i_{2}=\frac{i_{1}}{1+\left(t_{2}-t_{1}\right) \delta}
$$

The "temperature coefficient of the deflection" $\delta$ is defined by the relation

$$
\theta_{t}=\theta_{1}\left[1+\left(t-t_{1}\right) \delta\right]
$$

in which $\theta_{1}$ is the deflection, for a given current in the moving coil, at temperature $t_{1}$, and $\theta_{\mathrm{t}}$ is the deflection, for the same current, at temperature $t$. Values of $\delta$ for nine instruments examined in this laboratory ranged from +0.0001 to +0.0003 .

It follows from eqs 6 and 9 that for equality of deflections for the same voltage, at temperatures $t_{1}$ and $t_{2}, i_{2}$ must satisfy the equation

$$
i_{2}=\frac{e}{\left(a_{1}+c_{1}+\frac{a_{1} c_{1}}{b_{1}}\right)\left[1+\left(t_{2}-t_{1}\right) \delta\right]}
$$

The denominators of the right-hand members of eq 8 and 11 may now be equated, giving

$$
\begin{gathered}
a_{1}\left[1+\left(t_{2}-t_{1}\right) \alpha\right]+ \\
c_{1}\left[1+\left(t_{2}-t_{1}\right) \gamma\right]+\frac{a_{1}\left[1+\left(t_{2}-t_{1}\right) \alpha\right] c_{1}\left[1+\left(t_{2}-t_{1}\right) \gamma\right]}{b_{1}\left[1+\left(t_{2}-t_{1}\right) \beta\right]} \\
=\left(a_{1}+c_{1}+\frac{a_{1} c_{1}}{b_{1}}\right)\left[1+\left(t_{2}-t_{1}\right) \delta\right]
\end{gathered}
$$

from which

$$
c_{1}=\frac{b_{1}\left(t_{2}-t_{1}\right)(\alpha-\delta)}{1+\frac{a_{1}+b_{1}}{a_{1}}\left(t_{2}-t_{1}\right) \delta-\frac{b_{1}}{a_{1}}\left(t_{2}-t_{1}\right) \gamma-\frac{\left[1+\left(t_{2}-t_{1}\right) \alpha\right]\left[1+\left(t_{2}-t_{1}\right) \gamma\right]}{1+\left(t_{2}-t_{1}\right) \beta}}
$$

The $c$ coil should preferably be made of wire of negligible temperature coefficient, as assumed by previous writers. Putting ${ }^{12} \gamma=0$ in eq 13 reduces it to the form

$$
c_{1}=\frac{b_{1}(\alpha-\delta)}{\frac{a_{1}+b_{1}}{a_{1}} \delta+\frac{\beta-\alpha}{1+\left(t_{2}-t_{1}\right) \beta}}
$$

This exact expression for the resistance of the coil $c$, in which the temperature coefficient $\delta$ of the constant-current deflection has been correctly introduced, is only slightly more involved than the inexact expressions hitherto published. The presence of the quantity $t_{2}-t_{1}$ in eq 13 and 14 shows that exact compensation is theoretically possible for only one temperature other than the one at which the instrument is adjusted. In comparing the exact expression, eq 14,

\footnotetext{
12 It is desirable to have $\gamma=0$, and when the millivoltmeter is to indicate the difference of potential between its terminals $\gamma$ would always be made zero. When the millivoltmeter is calibrated to indicate the potential difference at its terminals plus the drop in a pair of copper leads, it is necessary to use eq 13 because the leads are effectively part of the $c$ coil.
} 
with those given by earlier writers, it should be noted that although the temperature coefficient $\delta$ is much smaller than $\beta$ or $\alpha$ it appears in the equation multiplied by $(a+b) / a$, which in a good design may have a numerical value of 5 or more; and furthermore, this multiple of $\delta$ is here associated with the difference of $\beta$ and $\alpha$. The necessity for the use of the exact formula is evident.

\section{IMPORTANT REQUIREMENTS OTHER THAN COMPENSATION}

The formulas given by previous writers, as well as eqs 13 and 14 just given, are of academic interest but of little value to the instrument designer because they fail to take account of three practical requirements, all of which must be considered in the design of a high-grade compensated millivoltmeter. These requirements are (a) the millivoltmeter must give full-scale deflection for a stated round value of potential difference, for example, 50 or 100 millivolts; (b) its resistance should have a specified round value, for example, $10 \mathrm{ohms}$; and (c) the motion of the moving coil should be properly damped. Formulas are given in this paper for the conditions to be met for temperature compensation with any one of these three additional requirements; for compensation with any two of them; and for compensation with all three of them. This last case, because of its great usefulness to the instrument designer, will be taken up first and will be treated in much greater detail than the other six cases.

\section{COMPENSATION WITH SPECIFIED FULL-SCALE POTENTIAL DIFFERENCE, SPECIFIED RESISTANCE OF THE MILLIVOLT- METER, AND SPECIFIED TOTAL DAMPING RESISTANCE}

It is assumed that the designer has a particular millivoltmeter mechanism ${ }^{13}$ for which the resistance $a_{1}^{\prime}$ of the moving coil and springs (at reference temperature $t_{1}$ ) is known, as well as the current $i_{f 1}$ which will produce full-scale deflection at this temperature. The finished millivoltmeter is to give full-scale deflection, at reference temperature $t_{1}$ and a second chosen temperature $t_{2}$, for a stated potential difference $e_{f}$ between its terminals; the resistance of the millivoltmeter, at reference temperature $t_{1}$, is to be $r_{1}$. There is also specified a total damping resistance $d_{1}$, which relates to the use of the millivoltmeter with a shunt and is defined (see fig. 3) as the sum of the resistances $a_{1}^{\prime}$ and $a_{1}^{\prime \prime}$, plus the resultant resistance of $b_{1}$ and $c_{1}$ in parallel. . It is assumed in this definition that the resistance of the shunt $S$ in figure 3 is negligibly small in comparison with the other resistances involved. Figure 3 is introduced at this point merely to illustrate the significance of the "total damping resistance" thus arbitrarily defined. The following analysis, however, relates to the case of the millivoltmeter used without a shunt, and should be read with reference to the diagram of figure 1 .

It is convenient to replace the specified full-scale potential difference $e_{f}$ and the known full-scale current $i_{f}$ by a quantity which will

\footnotetext{
13 The term "mechanism" as applied to indicating electrical instruments is defined as follows in American Standards for Electrical Indicating Instruments, in preparation at this writing:

"The mechanism of an indicating instrument is the arrangement of parts for producing and controlling the motion of the pointer. It includes all the essential parts necessary to produce these results but does not include the base, cover, scale, or any parts, such as series resistors or shunts, whose function is to adapt the range of the instrument to the quantity to be measured."
} 
be called the "sensitivity resistance" and will be denoted by the symbol $s$. It is given by the equation

$$
s=\frac{e_{f}}{i_{f}}
$$

and is simply the total resistance which the millivoltmeter would have if its electrical circuit consisted only of the moving coil and springs, plus enough series resistance to make the full-scale deflection correspond to a potential difference $e_{f}$ between the terminals. ${ }^{14}$ This quantity $s$ is really a special value of $q$ which complies with a required value of $e_{f}$ and the value of $i_{f}$ which applies to a particular mechanism. It might have been designated by the symbol $q$ with a special subscript, but for simplicity it is designated by the symbol $s$. The subscript 1 indicates the value which corresponds to reference temperature.

It is required to find (1) the values of $a_{1}, b_{1}$, and $c_{1}$ which will give $r_{1}$ and $d_{1}$ the required values and also satisfy the requirement as to $e_{f}$; and (2), to find the values of the temperature coefficients $\alpha, \beta$, and $\gamma$ which will cause the deflection at temperature $t_{2}$ to be the same as at

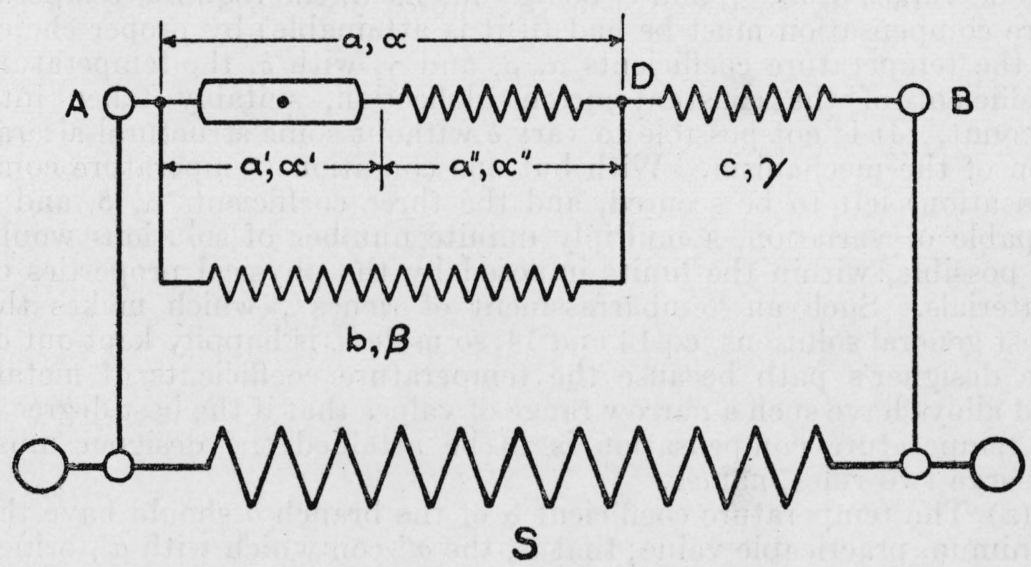

Figure 3.-Diagram of a Swinburne-compensated millivoltmeter connected to a shunt $S$ for the measurement of current.

the temperature $t_{1}$, for the same potential difference between the millivoltmeter terminals. To begin with (1) it is necessary to have three equations which involve $a_{1}, b_{1}, c_{1}, r_{1}, s_{1}$, and $d_{1}$.

A comparison of eq 6 and 15 will show that $s_{1}$ must be equal to $q_{1}$, that is,

from which

$$
s_{1}=a_{1}+c_{1}+\frac{a_{1} c_{1}}{b_{1}}
$$

$$
a_{1} b_{1}+a_{1} c_{1}+b_{1} c_{1}-b_{1} s_{1}=0
$$

The resistance of the millivoltmeter at reference temperature is

from which

$$
r_{1}=\frac{a_{1} b_{1}}{a_{1}+b_{1}}+c_{1}
$$

$$
a_{1} b_{1}+a_{1} c_{1}+b_{1} c_{1}-a_{1} r_{1}-b_{1} r_{1}=0
$$

${ }_{14}$ Instead of expressing $e_{f}$ and $i_{f}$ in volts and amperes, it is convenient to express $e_{f}$ in millivolts and $i_{f}$ in milliamperes. Each procedure gives $s$ in ohms. 
The total damping resistance at the reference temperature is

from which

$$
d_{1}=a_{1}+\frac{b_{1} c_{1}}{b_{1}+c_{1}}
$$

$$
a_{1} b_{1}+a_{1} c_{1}+b_{1} c_{1}-b_{1} d_{1}-c_{1} d_{1}=0
$$

$\mathrm{Eq} 17,19$, and 21 uniquely determine the values of $a_{1}, b_{1}$, and $c_{1}$, without any reference whatever to the matter of temperature compensation. The solution of these three equations gives

$$
\begin{aligned}
a_{1} & =\frac{s_{1} d_{1}\left(s_{1}-r_{1}\right)}{s_{1}^{2}-d_{1} r_{1}} \\
b_{1} & =\frac{s_{1} d_{1} r_{1}}{s_{1}{ }^{2}-d_{1} r_{1}} \\
c_{1} & =\frac{s_{1} r_{1}\left(s_{1}-d_{1}\right)}{s_{1}^{2}-d_{1} r_{1}}
\end{aligned}
$$

The values of $a_{1}, b_{1}$, and $c_{1}$ being thus fixed, the required temperature compensation must be had (if it is attainable) by proper choice of the temperature coefficients $\alpha, \beta$, and $\gamma$, with $\delta$, the temperature coefficient of the constant-current deflection, suitably taken into account. It is not possible to vary $\delta$ without some structural alteration of the mechanism. With but one condition (temperature compensation) left to be secured, and the three coefficients $\alpha, \beta$, and $\gamma$ capable of variation, a multiply infinite number of solutions would be possible, within the limits imposed by the physical properties of materials. Such an "embarrassment of riches", which makes the most general solutions, eq 13 and 14, so useless, is happily kept out of the designer's path because the temperature coefficients of metals and alloys have such a narrow range of values that if the best degree ${ }^{15}$ of temperature compensation is to be attained the designer must observe two rules, namely:

(a) The temperature coefficient $\alpha$ of the branch $a$ should have the minimum practicable value; that is, the $a^{\prime \prime}$ coil which with $a^{\prime}{ }_{1}$ brings up the resistance of the $a$ branch to the value $a_{1}$ given by eq 22 should be of manganin. ${ }^{16}$

(b) The temperature coefficient $\gamma$ of the coil $c$ should be zero, if possible. If the use of copper leads, included in the calibration of the millivoltmeter, makes a + value of $\gamma$ unavoidable, all of the rest of the $c$ branch should be of manganin.

The values of $\alpha$ and $\gamma$ thus being disposed of, the problem of temperature compensation is reduced to the determination of the value of $\beta$. It may be pointed out here that a failure to observe either of rules (a) and (b) gives an undesirable increase in the necessary value of $\beta$ and increases the departure of the line $o^{\prime} p^{\prime}$ from $o p$, figure 2 . Upper limits for $\beta$, for a reference temperature of $20^{\circ} \mathrm{C}$, are about 0.004 for copper and 0.006 for very pure iron and very pure nickel. The difficulties attending the commercial use of iron or nickel make it very desirable to be able to use copper in the $b$ branch, or a suitable

15 The best degree of temperature compensation is attained, for a given millivoltmeter mechanism and set of requirements, when the current-temperature curve $o^{\prime} p^{\prime}$ (fig. 2) departs from the ideal curve op by the minimum possible amount for temperatures between the specified upper and lower limits.

${ }_{16}$ It is theoretically possible to use an alloy for $a^{\prime \prime}$ with a slight negative temperature coefficient, but the reduction of $\alpha$ so obtained would be very small. Furthermore, some of the alloys with negative temperature coefficients of resistance are objectionable because their high thermal emf against copper might cause errors. 
combination of a copper coil and a manganin coil in series, if the required value of $\beta$ is lower than the temperature coefficient of pure copper.

An explicit solution for $\beta$ was derived and used in the course of the present investigation. It was so cumbersome, however, that a more practical procedure was sought and found. It consists of an explicit solution for $b_{2}$, from which $\beta$ may readily be found, and is carried out as follows:

Values of $a_{1}, b_{1}$, and $c_{1}$ having been computed by the use of eq 22 to 24 , inclusive, $\alpha$ is computed on the assumption that the coil $a^{\prime \prime}$ is to be of manganin, and $\gamma$ is assumed to be zero unless copper leads ${ }^{17}$ are to be included in the calibration, in which case the small + value of $\gamma$ is computed from the resistance of the two leads and that of the (manganin) $c$ coil itself. Values of $a_{2}$ and $c_{2}$ are then computed by the appropriate formulas, eq 7 . Then the equivalent series resistance (compare eq 3 ) at temperature $t_{2}$ is

$$
q_{2}=a_{2}+c_{2}+\frac{a_{2} c_{2}}{b_{2}}
$$

To maintain the deflection unchanged at the higher temperature, $b_{2}$ must have a value such that

that is,

$$
q_{2}=q_{1}\left[1+\left(t_{2}-t_{1}\right) \delta\right]
$$

$$
a_{2}+c_{2}+\frac{a_{2} c_{2}}{b_{2}}=\left(a_{1}+c_{1}+\frac{a_{1} c_{1}}{b_{1}}\right)\left[1+\left(t_{2}-t_{1}\right) \delta\right]
$$

in which the only unknown is $b_{2}$. The solution gives

$$
\begin{aligned}
b_{2} & =\frac{a_{2} c_{2}}{\left(a_{1}+c_{1}+\frac{a_{1} c_{1}}{b_{1}}\right)\left[1+\left(t_{2}-t_{1}\right) \delta\right]-a_{2}-c_{2}} \\
& =\frac{a_{2} c_{2}}{s_{1}\left[1+\left(t_{2}-t_{1}\right) \delta\right]-a_{2}-c_{2}}
\end{aligned}
$$

After the numerical value of $b_{2}$ has been found by substitution in this equation, the numerical value of $\beta$ may be found from the relation

$$
\beta=\frac{b_{2}-b_{1}}{b_{1}\left(t_{2}-t_{1}\right)}
$$

With a reference temperature of $20^{\circ} \mathrm{C}$, for example, if the required value of $\beta$ is 0.0039 or less, the $b$ coil can be made of copper, or partly of copper and the remainder of manganin. If $\beta$ must be greater than 0.0039 but not over 0.0058 , it will be necessary to make the $b$ coil of iron or nickel, alone or in combination with wire having a temperature coefficient lower than that of these metals. Extremely pure iron or nickel is necessary to attain the figure 0.0058 at reference temperature of $20^{\circ} \mathrm{C}$. If the value of $\beta$ as computed from eq 30 exceeds 0.0058 , the chosen requirements are too exacting to be realized with materials now available.

The copper, iron, or nickel part of the $b$ branch should be constructed and mounted so that its temperature will follow that of the moving coil very closely. Some tests by the author show that sufficient attention has not always been given to this point. The

17 One of the copper leads virtually forms part of the coil $c$ (fig. 1) and the other lead, though connected to the terminal $A$, is electrically also a part of coil $c$. 
method adopted by him consists in winding the copper part of the $b$ branch on a brass spool which is held firmly by a screw to the under side of the brass bracket which supports the scale plate.

\section{NUMERICAL EXAMPLE OF THE PRECEDING CASE}

Example 1.-A millivoltmeter mechanism of good (though not the most modern) design was available for a practical trial of the formulas developed in the preceding section. The desirable slightly underdamped motion of the coil occurred when the resistance across its terminals was $5.7 \mathrm{ohms}$. Its essential data were as follows:

Resistance $a_{1}^{\prime}$ of moving coil and springs, at $t_{1}=20^{\circ} \mathrm{C} \ldots \ldots \ldots \ldots$ ohms.

Temperature coefficient $\alpha^{\prime}$ of resistance of moving coil and springs,

at $20^{\circ} \mathrm{C}_{\ldots} \ldots$

Current $i_{f 1}$ in moving coil for full-scale deflection, at $20^{\circ} \mathrm{C}_{-}$

Temperature coefficient $\delta$ of the constant-current deflection.... $0.0001 /{ }^{\circ} \mathrm{C}$.

Total resistance $d_{1}$ for the desired slightly under-damped motion of

coil, at $20^{\circ} \mathrm{C}$

7.264 ohms.

The second chosen temperature $t_{2}$, at which the compensation should be exact, was $30^{\circ} \mathrm{C}$. The desired full-scale potential difference $\boldsymbol{e}_{\boldsymbol{f}}$ was 50 millivolts. The "sensitivity resistance" is (see eq 15)

$$
s_{1}=\frac{e_{f}}{i_{f 1}}=\frac{50}{3.634}=13.759 \mathrm{ohms} .
$$

The resistance $r_{1}$ of the millivoltmeter must be less than $s_{1}$. The value desired was $10 \mathrm{ohms}$. The substitution of the values of $s_{1}$, $r_{1}$, and $d_{1}$ in eq 22 to 24 , inclusive, gives the following values:

$$
\begin{aligned}
& a_{1}=3.220 \text { ohms. } \\
& b_{1}=8.5665 \text { ohms. } \\
& c_{1}=7.660 \text { ohms. }
\end{aligned}
$$

It was assumed that the millivoltmeter would be adjusted to read the potential difference between its terminals, and hence $\gamma$ was taken as zero. Consequently, $c_{2}=c_{1}=7.660 \mathrm{ohms}$. It was also assumed that $a^{\prime \prime}$ would be of manganin, of zero temperature coefficient, consequently,

$$
\begin{aligned}
a_{2} & =a_{1}+a_{1}^{\prime} \alpha^{\prime}\left(t_{2}-t_{1}\right) \\
& =3.220+(1.564 \times 0.0034 \times 10) \\
& =3.273 \mathrm{ohms} .
\end{aligned}
$$

The substitution of this value, with those of $c_{2}, s_{1}, t_{1}, t_{2}$, and $\delta$ in eq 29 , gives

$$
b_{2}=8.8286 \text { ohms. }
$$

The substitution of this value, with those of $b_{1}, t_{1}$, and $t_{2}$, in eq 30 , gives

$$
\beta=0.00306
$$

These computed results may be checked as follows:

The resistance of the millivoltmeter at reference temperature, by eq 18 , is 


$$
\begin{aligned}
r_{1} & =7.660+\frac{3.220 \times 8.5665}{3.220+8.5665} \\
& =10.000 \mathrm{ohms} .
\end{aligned}
$$

The total damping resistance at reference temperature, by eq 20 , is

$$
\begin{aligned}
d_{1} & =3.220+\frac{8.5665 \times 7.660}{8.5665+7.660} \\
& =7.264 \mathrm{ohms} .
\end{aligned}
$$

The equivalent series resistance $q_{1}$ at reference temperature, by eq 3 , is

$$
\begin{aligned}
a_{1}+c_{1}+\frac{a_{1} c_{1}}{b_{1}} & =3.220+7.660+\frac{3.220 \times 7.660}{8.5665} \\
& =13.759 \mathrm{ohms} .
\end{aligned}
$$

The correctness of the computed value of $\beta$ may be checked as follows: At the temperature $t_{2}=30^{\circ}$ the equivalent series resistance becomes

$$
\begin{aligned}
a_{2}+c_{2}+\frac{a_{2} c_{2}}{b_{2}} & =3.273+7.660+\frac{3.273 \times 7.660}{8.8286} \\
& =13.773 \mathrm{ohms} .
\end{aligned}
$$

The current which 50 millivolts will pass through this resistance is $50 / 13.773=3.6303$ milliamperes. The current required to produce

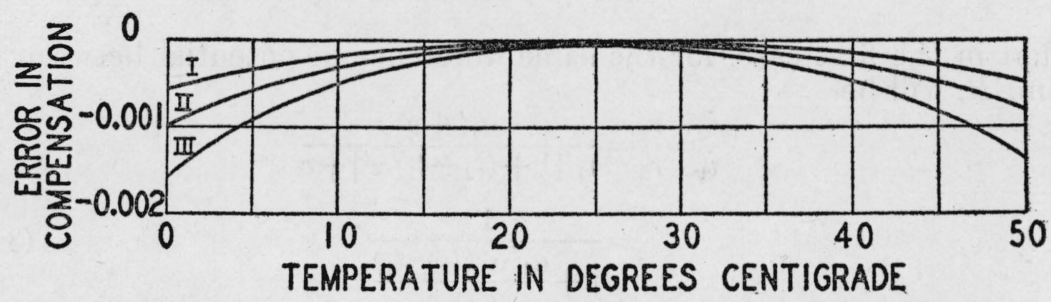

FIGURE 4.-Curves showing the error in compensation for the millivoltmeter of example 1.

Curve $I$ is for the optimum condition for which $\alpha$ is a minimum and $\gamma=0$. Curve $I I$ is for $\beta=0.004$ and $\alpha$ increased correspondingly. Curve III is for the minimum value of $\alpha, \gamma=0.0002$, and $\beta$ correspondingly increased.

full-scale deflection at $30^{\circ} \mathrm{C}$ is $3.634 / 1.001$ equals 3.6304 milliamperes. The small discrepancy in these two results, which corresponds to an imperceptibly small fraction of a scale division, is the result of "rejection error" in the calculations and not of any inexactness of the formulas used.

In figure 4, curve $I$ shows the computed performance of the millivoltmeter compensated as in the above example. To illustrate the desirability of keeping $\alpha$ and $\gamma$ as low as possible, two other curves are shown; $I \dot{I}$, in which $\beta$ is arbitrarily made equal to 0.004 and $\alpha$ is raised to 0.00208 to correspond; III, in which $\alpha$ has its desirable minimum value but $\gamma$ is given the value 0.0004 , which compels $\beta$ to take the value 0.00459 . It may be noted that the curve $I$ shows 
the least departure from the ideal straight-line compensation. The need for keeping $\gamma$ low is seen from the fact that giving it the value 0.0004 , which is equivalent to making the $c$ coil of one-tenth copper and nine-tenths manganin, raises $\beta$ to a value which makes some iron (or nickel) necessary in the $b$ coil and triples the departure from compensation as compared with the optimum condition.

\section{USE OF A MILLIVOLTMETER WITH A SHUNT FOR MEASURING CURRENT}

\section{TEMPERATURE COMPENSATION OF A SIMPLE SERIES- COMPENSATED MILLIVOLTMETER}

Figure 5 shows diagrammatically the circuit of a simple seriescompensated millivoltmeter. Its resistance at temperature $t_{1}$ is

$$
r_{1}=a_{1}^{\prime}+c
$$

and at temperature $t_{2}$ is

$$
r_{2}=a_{1}^{\prime}\left[1+\alpha^{\prime}\left(t_{2}-t_{1}\right]+c\right.
$$

on the assumption that the resistance $c$ is unaffected by the change of temperature. Then the ratio of the current in the second case to

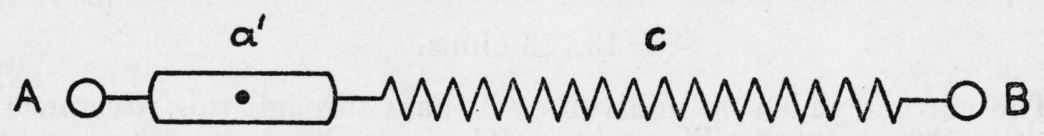

FIGURE 5.-Circuit of a millivoltmeter compensated for temperature by a series resistor $c$ of manganin.

that in the first case, for the same difference of potential between $A$ and $B$, will be

$$
\begin{aligned}
\frac{i_{2}}{i_{1}}=\frac{r_{1}}{r_{2}} & =\frac{a_{1}{ }^{\prime}+c}{a_{1}{ }^{\prime}\left[1+\left(t_{2}-t_{1}\right) \alpha^{\prime}\right]+c} \\
& =\frac{1}{1+\frac{a_{1}{ }^{\prime} \alpha^{\prime}\left(t_{2}-t_{1}\right)}{a_{1}^{\prime}+c}}
\end{aligned}
$$

The decrease in the current at the higher temperature $t_{2}$ will not reduce the deflection by the same relative amount because of the greater current sensitivity of the millivoltmeter mechanism at the higher temperature. This effect, already mentioned, is numerically stated in terms of the temperature coefficient $\delta$ of the constant-current deflection, and because of it the ratio of the deflection $\theta_{2}$ at temperature $t_{2}$ to the deflection $\theta_{1}$ at temperature $t_{1}$ will be

$$
\frac{\theta_{2}}{\theta_{1}}=\frac{i_{2}}{i_{1}}\left[1+\left(t_{2}-t_{1}\right) \delta\right]
$$

Combined with eq. 31 , this gives

$$
\frac{\theta_{2}}{\theta_{1}}=\frac{1+\left(t_{2}-t_{1}\right) \delta}{1+\frac{a_{1}^{\prime} \alpha^{\prime}\left(t_{2}-t_{1}\right)}{a_{1}^{\prime}+c}}
$$


For exact temperature compensation $\theta_{2} / \theta_{1}$ becomes unity, and

$$
\frac{a_{1}{ }^{\prime}}{a_{1}{ }^{\prime}+c} \cdot \alpha^{\prime}=\delta
$$

Thus for the usual average values, $\alpha^{\prime}=0.004$ and $\delta=0.0002, c$ must be 19 times $a^{\prime}{ }_{1}$ for exact compensation. If $c$ is less than $19 a_{1}{ }^{\prime}$, the millivoltmeter will be under-compensated, and $\theta_{2}$ will be less than $\theta_{1}$; if $c$ is greater than $19 a_{1}{ }^{\prime}$, the millivoltmeter will be over-compensated and $\theta_{2}$ will be greater than $\theta_{1}$.

\section{USE OF A SHUNT WITH A SIMPLE SERIES-COMPENSATED MILLIVOLTMETER AFFECTS THE TEMPERATURE COMPENSATION}

If a millivoltmeter which is wholly or partially compensated for temperature, either by the use of a manganin resistor in series with the moving coil (fig. 5) or by the Swinburne method, be used with a shunt as an ammeter, the degree of compensation as millivoltmeter and as ammeter will (in general) not be the same. The unlikely conditions, for which the degree of compensation will be the same in each case, are that the millivoltmeter and the shunt shall have the same temperature coefficient of resistance and that both shall be at the same temperature when they are used together as an ammeter. Although it is possible to make the shunt of the proportions of manganin and copper which will give the shunt a temperature coefficient of resistance equal to that of the millivoltmeter, it is usually impracticable to keep the shunt and the millivoltmeter at the same temperature. This is particularly true of shunts for large currents, in which the power loss is large enough to raise the temperature of the shunt considerably. It is therefore preferable that the shunt should be of manganin or material of similar characteristics.

\section{TEMPERATURE COMPENSATION OF AN AMMETER CONSISTING OF A SERIES-COMPENSATED MILLIVOLTMETER CONNECTED TO A SHIUNT}

During the present investigation a useful theorem was discovered which facilitates the analysis of the problem of temperature compensation of a shunted millivoltmeter used as an ammeter. Together with an old and apparently little-known theorem given by Feussner, it points out the most convenient and rational values of resistance of shunts to be used with millivoltmeters. For convenience in subsequent reference these two theorems will be numbered.

Theorem 1.- The degree of temperature compensation of a millivoltmeter with a shunt, used as an ammeter, is the same as the degree of temperature compensation which the millivoltmeter would have if it were connected in series with the shunt, now serving as a multiplier, the combination being used as a millivoltmeter. This case is illustrated diagrammatically in figure 6 , in which $S$ denotes the shunt and also its resistance, which is assumed for convenience to be invariable with temperature. For this case, by eq 33, the ratio of the deflection at temperature $t_{2}$ to the deflection at temperature $t_{1}$ is

$$
\frac{\theta_{2}}{\bar{\theta}_{1}}=\frac{1+\left(t_{2}-t_{1}\right) \delta}{1+\frac{a_{1}^{\prime} \alpha^{\prime}\left(t_{2}-t_{1}\right)}{a_{1}{ }^{\prime}+c+S}}
$$


Now let the connections become those shown in figure 7, which shows the millivoltmeter connected to the shunt in the usual manner for

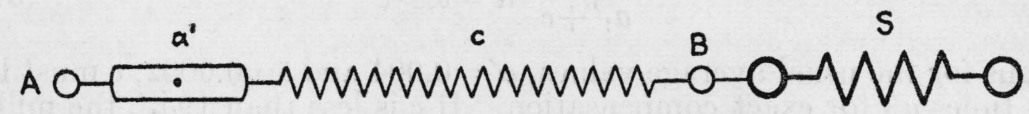

FIgURE 6.-Series-compensated millivoltmeter connected in series with a shunt $S$ which would normally be in parallel with the millivoltmeter (see fig. 7) for the measurement of a current.

the measurement of a current $I$. At the reference temperature $t_{1}$ the current through the moving coil of the millivoltmeter will be

$$
i_{1}=\frac{I S}{a_{1}^{\prime}+c+S}
$$

and the deflection will be $\theta_{1}$. At temperature $t_{2}$,

$$
\begin{aligned}
i_{2} & =\frac{I S}{a_{1}^{\prime}\left[1+\left(t_{2}-t_{1}\right) \alpha^{\prime}\right]+c+S} \\
\frac{\theta_{2}}{\theta_{1}} & =\frac{i_{2}}{i_{1}}\left[1+\left(t_{2}-t_{1}\right) \delta\right] \\
& =\frac{a_{1}{ }^{\prime}+c+S}{a_{1}{ }^{\prime}\left[1+\left(t_{2}-t_{1}\right) \alpha^{\prime}\right]+c+S} \cdot\left[1+\left(t_{2}-t_{1}\right) \delta\right] \\
& =\frac{1+\left(t_{2}-t_{1}\right) \delta}{1+\frac{a_{1}{ }^{\prime} \alpha^{\prime}\left(t_{2}-t_{1}\right)}{a_{1}{ }^{\prime}+c+S}}
\end{aligned}
$$

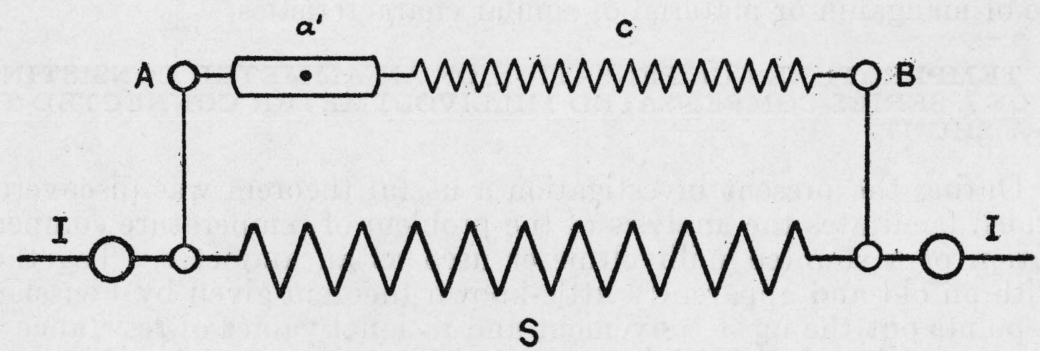

FIGURE 7.-Series-compensated millivoltmeter connected to a shunt $S$ for the measurement of a current.

This equation is identical with eq 35 . It shows that the resistance $S$ enters the denominator virtually as an increase in the value of $c$. If $c$ is inadequate for exact compensation as a millivoltmeter, and $S$ is not too large, the compensation as an ammeter will be better than as a millivoltmeter. It may now be seen why the use of manganin shunts for very small currents, the resistance of such shunts being relatively large, introduces relatively large temperature errors by over-compensation, if the millivoltmeter alone is well compensated as such. 
An obvious and important consequence of theorem 1 is that if any portion of the series resistor $c$ is removed and put in parallel with the remainder of the millivoltmeter circuit, the portion of $c$ removed being used as a shunt, the degree of temperature compensation as an ammeter will be the same as that of the millivoltmeter in its original condition, used to measure the potential difference at its terminals. This holds true even if all of $c$ is used as a shunt, for which case the apparently anomalous condition exists that an allcopper ${ }^{18}$ millivoltmeter mechanism, subject to a temperature error of nearly 0.4 percent per degree centigrade when used as a millivoltmeter, will have a zero temperature error when used as an ammeter, with a manganin shunt having a particular value of resistance. This fact shows how a millivoltmeter may be used to measure small currents without the usual large temperature error, namely, by reducing the series resistance $c$ of the millivoltmeter by an amount equal to the resistance of the shunt, if the millivoltmeter as such is entirely compensated. If it is not, and it is desired to make the combination, millivoltmeter and shunt, exactly compensated as an ammeter, the sum of the resistance $S$ of the shunt and the resistance $c$ of the manganin coil in the millivoltmeter should have the value which $c$ ought to have for exact compensation of the millivoltmeter used as such.

The removal of a part of $c$ to serve as a shunt can be effected by the equivalent procedure shown in figure 8 . Here the millivoltmeter is

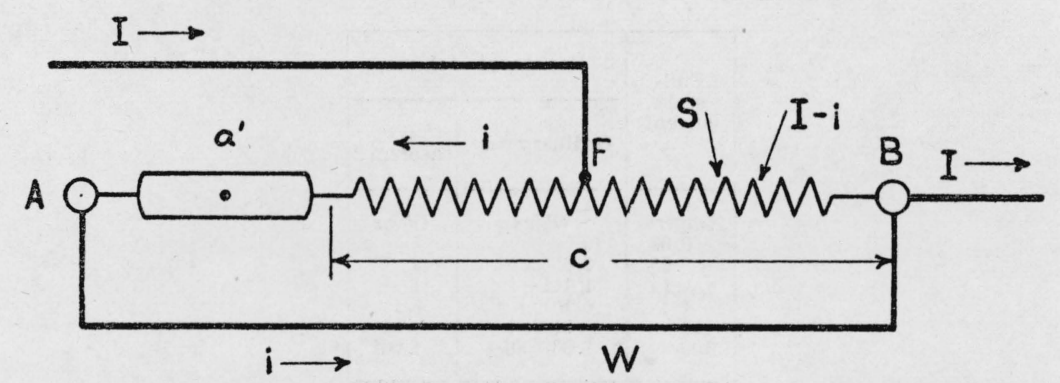

FIGURE 8.-Series-compensated millivoltmeter with its terminals joined by a wire $W$ of negligible resistance.

A portion $S$ of the manganin resistor $c$ is used as an ammeter shunt in the measurement of a current $I$. The degree of temperature compensation is the same as that of the millivoltmeter used alone as such.

shown as short-circuited by a wire $W$ of negligible resistance, and the current $I$ to be measured is introduced at a point $F$ on the resistor $c$ and leaves at the point $B$.

The ordinary method of using shunts for the measurement of relatively small currents has another disadvantage besides that of affecting the temperature compensation, namely, the resistance of the shunt must be given an odd value which depends upon the resistance of the millivoltmeter. For example, the 1-ohm millivoltmeters used at one time were provided with shunts having resistances of $1 / 9,1 / 99, \ldots \ldots$ ohm. A usual resistance for compensated millivoltmeters today is $10 \mathrm{ohms}$. If the range in millivolts of such instruments is assumed to be the same as for the 1-ohm millivoltmeter, shunts for the former would need to be $10 / 99,10 / 999, \ldots . .$. ohm.

18 Strictly, the spiral springs are of alloy with a temperature coefficient less than that of copper, but the tatement would nevertheless hold, even if the springs were of copper. 
It is desirable not only to avoid the necessity for odd values but also to have the resistance of a shunt, for a given current and a given potential difference, independent of the resistance of the millivoltmeter with which it is to be used. It was shown by Feussner ${ }^{19}$ that the use of a part of the series resistance $c$ as the resistance $S$ of a shunt avoids the odd values and makes the resistance of the shunt independent of that of the millivoltmeter. Feussner's principle may be stated as follows:

Theorem 2.- If a millivoltmeter which gives a stated deflection for a potential difference $e$ at its terminals is used with a shunt to measure a current $I$ for which it is to give the same stated deflection, and if the series resistance of the millivoltmeter is reduced by an amount equal to the resistance of the shunt, then the resistance of the shunt will be $e / I$, regardless of the resistance of the millivoltmeter.

In other words, the resistance of the shunt in this case will have the value it would have if the shunt were to be used with a potentiometer, which is equivalent to a millivoltmeter of infinite resistance. The following table illustrates the difference between the resistances of five shunts which are adjusted in one case for use in the ordinary way with a 10-ohm millivoltmeter which gives full-scale deflection for 100 millivolts, and in the second case for use with this or any other millivoltmeter on the assumption that its series resistance is to be decreased by an amount equal to the resistance of the shunt.

TABLE 1.-Comparison of resistances of shunts

\begin{tabular}{|c|c|c|}
\hline $\begin{array}{c}\text { Full- } \\
\text { scale } \\
\text { current }\end{array}$ & \multicolumn{2}{|c|}{ Resistance of shunt } \\
\cline { 2 - 3 } & Ordinary case & $\begin{array}{c}\text { By } \\
\text { theorem 2 }\end{array}$ \\
\hline Amperes & \multicolumn{1}{|c|}{ Ohms } & Ohms \\
0.02 & 10 & 5 \\
.05 & 2.5 & 2 \\
.1 & $1.111+$ & 1 \\
1 & $0.1010+$ & 0.1 \\
10 & $.01001+$ & .01 \\
100 & $.0010001+$ & .001 \\
\hline
\end{tabular}

Above 10 amperes the differences become of little or no practical significance, but for small currents the advantage of adjustment to the round values of theorem 2 is obvious, especially when it is considered that the odd values of column 2 would be different for millivoltmeters of different resistances.

It follows from theorem 2 that if the series resistor $c$ be tapped to form a multirange shunt, as shown in figure 9, the resistances of the various sections $C B$ of the shunt will be inversely as the corresponding currents for a stated deflection of the millivoltmeter. Thus, theorem 2 includes the principle of the Ayrton-Mather universal galvanometer shunt. The theory of this shunt, however, as given by its inventors and by others since them, does not include the fact of which theorem 2 is a statement.

${ }_{10}$ Elektrotech. Z. 25, 115 (1904). 
It is obvious that if part of the series resistor $c$ is to be used as an ammeter shunt its cross section and its opportunity for giving off heat must be suitably increased. What is thought to be the most suitable method of utilizing the two theorems is shown in figure 10.

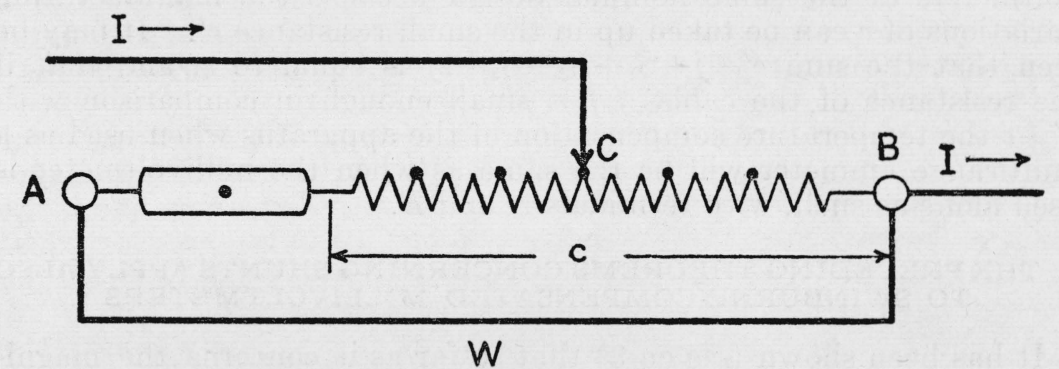

Figure 9.-Series-compensated millivoltmeter with its terminals joined by a wire W of negligible resistance.

The series resistor $c$ has a number of tap points traversed by the brush $C$. The apparatus constitutes a multirange ammeter. Each range has the degree of temperature compensation which the millivoltmeter has when used alone as such.

Here three manganin resistors, $S_{1}, S_{2}$, and $S_{3}$ are permanently connected in series to form an Ayrton-Mather set of three ammeter shunts of resistances $S_{1}, S_{1}+S_{2}$, and $S_{1}+S_{2}+S_{3}$ respectively. $A^{\prime}$ and

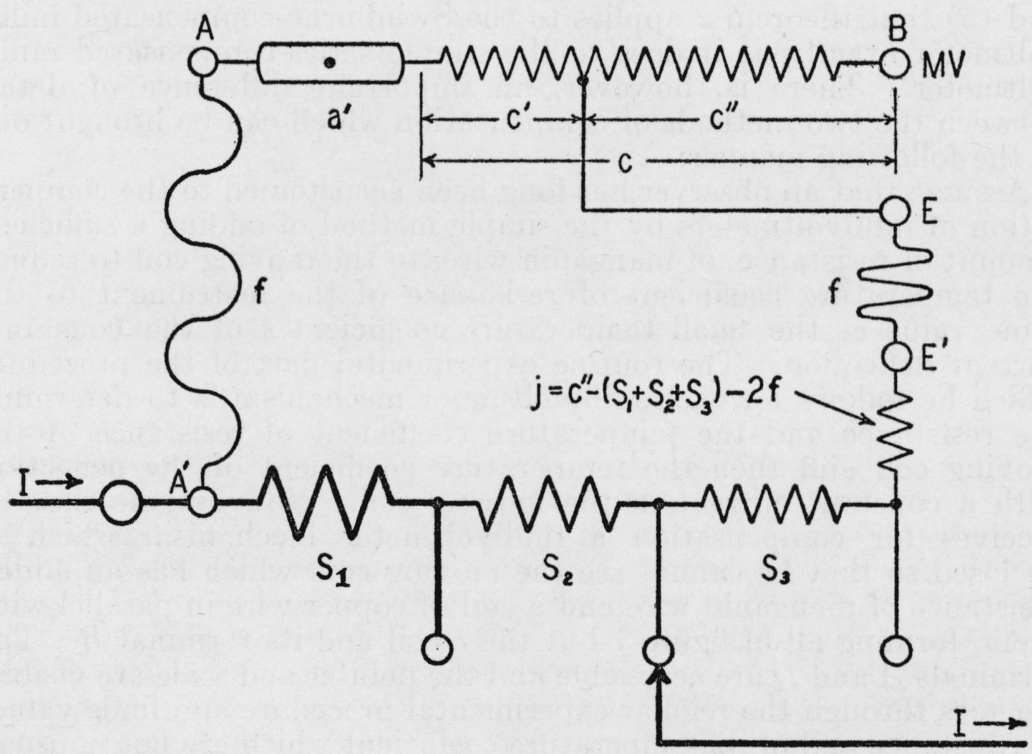

Figure 10.- Set of three shunts on the Ayrton-Mather plan, connected to a temperature-compensated millivoltmeter through a tap point on the series resistor $c$.

When the coil $j$ has the value indicated the temperature compensation of each current range is the same as that of the millivoltmeter used alone as such.

$E^{\prime}$ are the potential terminals of the shunt, and are removably attached to the millivoltmeter terminails $A$ and $E$ by links or flexible cords $f f$ of resistance which is either negligible or is allowed for in 
the adjustment of the coil marked $j$. It should be noted that the tap wire to the terminal $E$ is brought out from a point which divides the resistance $c$ into parts $c^{\prime}$ and $c^{\prime \prime}, c^{\prime \prime}$ being say three-fourths of $c$. This makes it possible to standardize the value of $c^{\prime \prime}$ for all millivoltmeters of the same nominal design because the manufacturing variations of $c$ can be taken up in the small resistance $c^{\prime}$. It may be seen that the sum $c^{\prime}+j+S_{1}+S_{2}+S_{3}+2 f$ is equal to $c$, and that if the resistance of the cables $f f$ is small enough in comparison with $a^{\prime}+c$ the temperature compensation of the apparatus when used as a multirange ammeter will be the same as when the millivoltmeter is used alone as such, with terminals $A$ and $B$.

\section{THE PRECEDING THEOREMS CONCERNING SHUNTS APPLY ALSO TO SWINBURNE-COMPENSATED MILLIVOLTMETERS}

It has been shown (see eq 3 ) that so far as it concerns the magnitude of the current $i$ in the moving coil $a^{\prime}$ when a potential difference $e$ is applied to the terminals $A$ and $B$ (see fig. 1), the network may be replaced by an equivalent simple series circuit consisting of the moving coil $a$ and the coil $c$ plus an increment $a c / b$ to the coil $c$. It may readily be shown, in the manner used in the preceding section, (a) that the degree of temperature compensation of a Swinburnecompensated millivoltmeter, used with a shunt as an ammeter, is the same as the degree of compensation which would exist if the shunt were put in series with the millivoltmeter to extend its range as such; and (b) that theorem 2 applies to the Swinburne-compensated millivoltmeter exactly as it does to the simple series-compensated millivoltmeter. There is, however, an important difference of detail between the two methods of compensation which can be brought out in the following manner:

Assume that an observer has long been accustomed to the compensation of millivoltmeters by the simple method of adding a sufficient amount of resistance, of manganin wire, to the moving coil to reduce the temperature coefficient of resistance of the instrument to the same value as the small temperature coefficient $\delta$ of the constantcurrent deflection. The routine experimental part of the procedure which he follows for each millivoltmeter mechanism is to determine the resistance and the temperature coefficient of resistance of the moving coil and then the temperature coefficient of the deflection with a constant current in the moving coil. Now assume that he receives for compensation a millivoltmeter mechanism which is enclosed so that he cannot see the moving coil, which has an added resistance of manganin wire and a coil of copper wire in parallel with them, forming all of figure 1 but the $c$ coil and its terminal $B$. The terminals $A$ and $D$ are accessible and the pointer and scale are visible. He goes through the regular experimental procedure and finds values of resistance and of its temperature coefficient which are not unusual. On passing a definite current through the supposed simple coil, however, at the two temperatures, he is surprised to find that the constantcurrent deflection increases by as much as 0.2 percent per degree centigrade; in other words, that $\delta$ has an abnormal value about 10 times as great as would usually be found. He may lay this fact to the use of some new alloy for the springs, which seem to weaken, with a given increase of temperature, much more than all alloy springs he has previously tested; or to the use of an unusual kind of magnet 
steel for which the flux density in the air gap seems to increase with temperature at a rate previously unknown. In any event, the high value of $\delta$ shows him that this particular mechanism may be compensated by the use of a manganin coil $c$ (fig. 1) having the relatively low resistance which will make the temperature coefficient of resistance of the instrument equal to the abnormally large value of $\delta$. It will then be apparent to him that the use of a manganin shunt, of resistance comparable with that of the millivoltmeter, will affect the compensation by say 0.1 percent per degree centigrade; and that in the extreme case of a shunt of infinite resistance (that is, when the millivoltmeter is used as a milliammeter with the whole current passing through it) the defect in the compensation will be equal to $\delta$, that is, it may be 0.2 percent per degree centigrade. For comparison, the defect in compensation when a series-compensated millivoltmeter is used as a milliammeter is only about 0.02 percent per degree centigrade.

The above reasoning shows that in the measurement of small currents with Swinburne-compensated millivoltmeters and relatively high-resistance manganin shunts much greater defects in temperature compensation exist than when series-compensated millivoltmeters are used. This fact has long been known. Keinath ${ }^{20}$ states that the current in the shunt must be at least 10 times the instrument current, and that for the Siemens 10-ohm millivoltmeter, for example, the range of the smallest regularly listed shunt is 150 milliamperes, that is, over 30 times the instrument current. He adds that shunts are supplied for lower values down to 15 milliamperes but that these are applicable only for less accurate measurements. He states that the temperature error in this latter case may be compensated by making the shunt partly of manganin and the rest of copper, but that this procedure introduces the risk of error because the copper may be heated by the current in it and in the adjacent manganin and the instrument as a whole may show a temperature error. For this reason he concludes that this method of constructing shunts for small currents is inadvisable.

In contrast with this unsatisfactory state of affairs, the arrangement shown in figure 10 permits the use of a Swinburne-compensated millivoltmeter for currents as small as (for example) twice the instrument current with a degree of temperature compensation at least as good as that of the millivoltmeter used as such. If the millivoltmeter is only partially compensated when used alone, it is possible to choose the values of shunts, of even very low ranges, such that the compensation may be complete when the millivoltmeter is used with the shunts as an ammeter.

\section{MULTIRANGE SWINBURNE-COMPENSATED INSTRUMENTS}

\section{MULTIRANGE MILLIVOLTMETERS}

Figure 11 shows the manner in which a second, higher range would be provided in a simple series-compensated millivoltmeter. An additional manganin coil $c^{\prime}$ is provided and also a coil of copper wire $C u$ in close thermal proximity to the moving coil. If the temperature compensation of the first range (for the case of terminals $A$ and

${ }^{20}$ Die Technik elektrischer Messgeräte, 1st ed., p. 60; 2d ed., p. 66; 3d ed., vol. 1, p. 106.

$89799-36-3$ 
$B$ ) is exact, and that of the second range is also to be exact, the temperature coefficient of resistance of the part $B B^{\prime}$ would be made equal to that of the part $A B$; that is, equal to the value of $\delta$ for the particular millivoltmeter mechanism. Because of the relatively

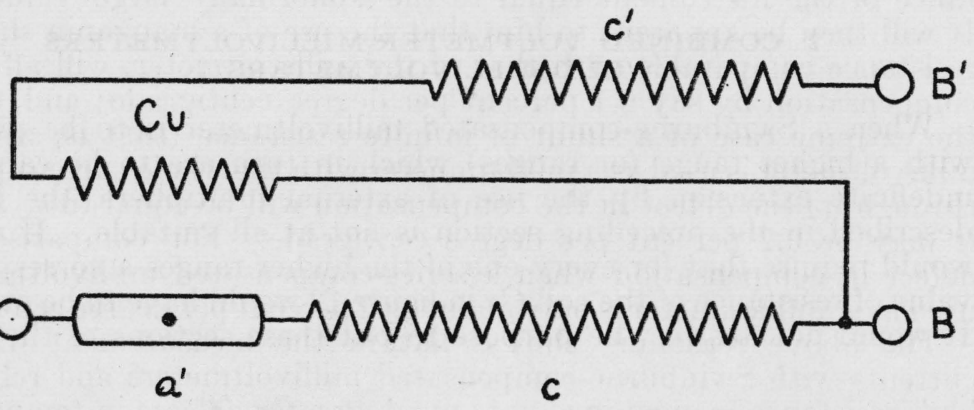

FIGURE 11.-Method of adding a second millivolt range to a series-compensated millivoltmeter, with maintained temperature compensation.

The copper coil $C u$ and the second manganin coil $c^{\prime}$ must have jointly the same temperature coefficient of resistance as the moving coil $a^{\prime}$ and the original manganin coil $c$.

small resistance of the coil $C u$ as compared with that of $c^{\prime}$ the necessary degree of equality of temperature of $C u$ and $a^{\prime}$ is very moderate for this case of simple series compensation.

Figure 12 shows the same procedure as applied to a Swinburnecompensated millivoltmeter. The principle of this case is exactly

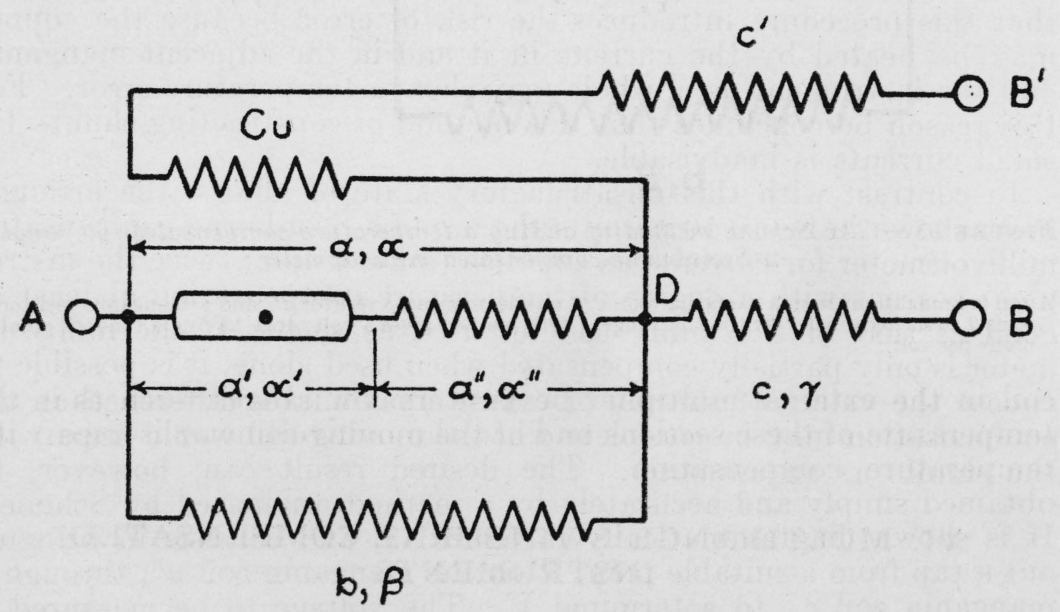

FIGURE 12.-One method of adding a second millivolt range to a Swinburne-compensated millivolimeter.

To maintain the original degree of temperature compensation the temperature coefficient of resistance of the network with $A$ and $B^{\prime}$ used as terminals must be the same as when $A$ and $B$ are used as terminals. The same value of ohms per volt applies to both ranges.

the same as that of the preceding case, in that the temperature coefficient of resistance of the part $\mathrm{DCu} \mathrm{B}^{\prime}$ is made equal to that of the part $A D B$. In the Swinburne case, however, the relative amount of resistance in the coil $C u$ is so much greater that this coil 
should be so made and supported as to follow the temperature of coils $a^{\prime}$ and $b$ very closely. This method of obtaining higner ranges is simple and gives the same number of ohms per volt on all ranges, but its use is preferably limited to higher ranges which are in the millivolt class. For still higher ranges another method is preferable.

\section{COMBINED VOLTMETER-MILLIVOLTMETERS} ("VOLT-MILLIVOLTMETERS")

When a Swinburne-compensated millivoltmeter is to be provided with a higher range (or ranges) which in turn are to be capable of indefinite extension by the use of external multipliers, the method described in the preceding section is not at all suitable. If used, it would require that for every one of the higher ranges a corresponding value of resistance of the coil $C u$ in figure 12 would have to be provided. It would not answer the purpose to put these sections of the copper

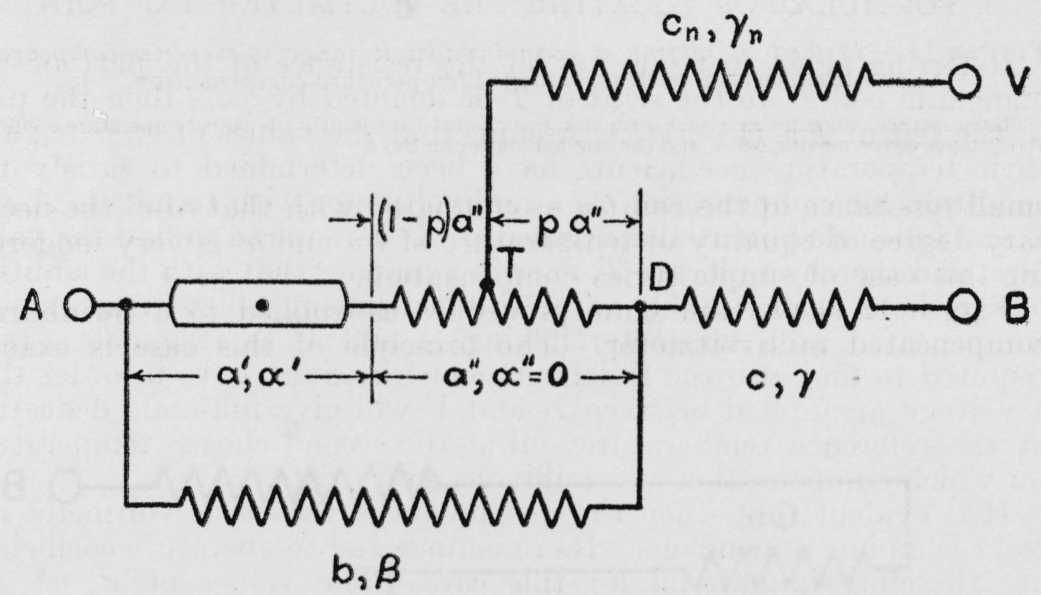

FIGURE 13.-The Schöne method of adding a temperature-compensated volt range to a Swinburne-compensated millivoltmeter.

A tap is brought out from a particular point $T$ on the manganin resistor $a^{*}$, and a manganin resistor $c_{n}$ joins $T$ to the terminal $V$ for the volt range. This method gives a volt range having a random $v a l u e$ of ohms per volt.

coil in the external multiplier because unavoidable differences in the temperature of these sections and of the moving coil would impair the temperature compensation. The desired result can, however, be obtained simply and accurately by a method originated by Schöne. ${ }^{21}$ It is shown diagrammatically in figure 13 , and consists in bringing out a tap from a suitable point $T$ on the manganin coil $a^{\prime \prime}$, through a manganin coil $c_{n}$, to a terminal $V$. The voltage to be measured is applied between the terminals $A$ and $V$, and the coil $c$ of the network is idle. If the temperature coefficient $\delta$ of the constant-current deflection were equal to zero, and if the resistance of $c_{n}$ were very high in comparison with that of the moving coil $a^{\prime}$, the tap point on $a^{\prime \prime}$ would be chosen so that the temperature coefficient of $a^{\prime}$ plus the part of $a^{\prime \prime}$ to the left of the tap point $T$ would be equal to the temperature coefficient of $b$ plus the part of $a^{\prime \prime}$ to the right of $T$. In the usual case

\footnotetext{
" O. Schöne, letter to editor, Elektrotech. Z. 33, 201 (1912).
} 
of a small positive value of $\delta$ and for a relatively high value of $c_{n}$, the tap point must be to the left of this position so that for a constant voltage between $A$ and $V$ (and hence a nearly constant current in $c_{n}$, regardless of temperature changes) the current in the moving coil will decrease with temperature at a rate equal to $\delta$. For a particular, relatively low value of $c_{n}$ and with a small positive value of $\delta$ the point $T$ would be chosen to give equal temperature coefficients to the two paths to the right and to the left of $T$. In this case the decrease in the current through the moving coil, at the higher temperature, results from the decrease in the current taken by the millivoltmeter because of the presence of copper in $a^{\prime}$ and $b$. For still lower ranges the point $T$ must move to the right in order to give the moving coil a greater share, at the higher temperature, of the decreased current taken by the voltmeter as a whole. For still lower ranges $T$ shifts further to the right until in the limit it coincides with $D$ for $c_{n}=c$.

\section{FORMULA FOR LOCATING THE VOLTMETER TAP POINT}

Referring again to figure 13 , let the resistance of the part of the manganin coil $a^{\prime \prime}$ to the right of $T$ be denoted by $p a^{\prime \prime}$, then the part to the left of $T$ is $(1-p) a^{\prime \prime}$. Assume that the values of $a_{1}, b_{1}, c_{1}$, and their temperature coefficients have been determined to satisfy the condition for compensation as a millivoltmeter with terminals $A$ and $B$ and full-scale potential difference $e$. It is required to find the value of $p$, and thereby to locate $T$, in such a manner that with the addition of a resistor $c_{n}$ of suitable value the instrument will be temperature compensated as a voltmeter having $A$ and $V$ as terminals. It is required to find also the resistance which $c_{n}$ must have in order that a voltage ne applied between $A$ and $V$ will give full-scale deflection at the reference temperature and at the second chosen temperature for which compensation as a millivoltmeter exists.

It is evident that when the instrument is used as a voltmeter the coil $c$ is an idle appendage. Its resistance and temperature coefficient are therefore immaterial for this case. The values of $a^{\prime}, a^{\prime \prime}, \alpha^{\prime}$, $b$, and $\beta$ must be left unchanged. It is assumed that $\alpha^{\prime \prime}$ is zero, since it is disadvantageous to have it otherwise. The temperature compensation as a voltmeter will depend upon the location of the tap point $T$, and upon the magnitude and the temperature coefficient $\gamma_{n}$ of the coil $c_{n}$. It is usually desirable to have $\gamma_{n}$ negligibly small by making the coil $c_{n}$ of manganin. There are thus two unknowns, $p$ and $c_{n}$, and two independent equations connecting them are required. The first one is obtained by ignoring the original coil $c$ and considering the remainder of the network as a Swinburne-compensated network in which the original branch $a\left(=a^{\prime}+a^{\prime \prime}\right)$ has become $a^{\prime}+(1-p) a^{\prime \prime}$, the original $b$ coil has become $b+p a^{\prime \prime}$, and the new coil $c_{n}$ replaces the original coil $c$. These new branches must satisfy an equation for temperature compensation, of the form of eq 14, namely,

$$
c_{n 1}=\left(b_{1}+p a^{\prime \prime}\right) \frac{\alpha_{n}-\delta}{\frac{a_{1}+b_{1}}{a_{1}+(1-p) a^{\prime \prime}} \cdot \delta+\frac{\beta_{n}-\alpha_{n}}{1+\left(t_{2}-t_{1}\right) \beta_{n}}}
$$


in which the temperature coefficients of the new $a$ and $b$ branches are

$$
\begin{aligned}
\alpha_{n} & =\frac{a_{{ }_{1} \alpha^{\prime}}}{a_{1}^{\prime}+(1-p) a^{\prime \prime}} \\
\beta_{n} & =\frac{b_{1} \beta}{b_{1}+p a^{\prime \prime}}
\end{aligned}
$$

The values of resistance of the three new branches must also satisfy the condition that the new equivalent series resistance $q_{n}$ must be $n$ times the original $q$ as a millivoltmeter; that is, for the reference temperature $t_{1}$

$$
a_{1}^{\prime}+(1-p) a^{\prime \prime}+c_{n 1}+\frac{\left[a_{1}^{\prime}+(1-p) a^{\prime \prime}\right] c_{n 1}}{b_{1}+p a^{\prime \prime}}=n\left(a_{1}+c_{1}+\frac{a_{1} c_{1}}{b_{1}}\right)
$$

The condition that $p$ shall satisfy eq 41 and 44 leads to the quadratic equation

$$
\begin{aligned}
& p^{2}+\frac{\left\{\left(n s_{1}-a_{1}\right)\left(a_{1} \alpha+b_{1} \beta\right)-\left(n s_{1} \delta-a_{1} \alpha\right)\left(a_{1}+b_{1}\right)-a_{1} b_{1}(\beta-\alpha)\right\} p}{a^{\prime \prime}\left(a_{1} \alpha+b_{1} \beta\right)}- \\
& -\frac{b_{1}\left\{\left(n s_{1} \delta-a_{1} \alpha\right)\left(a_{1}+b_{1}\right)\left[1+\left(t_{2}-t_{1}\right) \beta\right]+\left(n s_{1}-a_{1}\right) a_{1}(\beta-\alpha)\right\}}{a^{\prime \prime 2}\left(a_{1} \alpha+b_{1} \beta\right)}=0
\end{aligned}
$$

The solution of this equation for $p$, if left in its conventional form; would evidently be very inconvenient for use in computing numerical values, especially for the case of multirange voltmeters for which $p$ must be computed for several values of $n$. The following exact formula is the result of an effort to express $p$ in such a way as to minimize the labor of computation:

$$
p=n P \frac{-\left(1-\frac{S}{n}\right)+\left[\left(1-\frac{S}{n}\right)^{2}+\frac{4(n-1) U}{n^{2}}\right]^{\frac{1}{2}}}{2}
$$

in which

$$
\begin{gathered}
P=\frac{s_{1}\left[a_{1}(\alpha-\delta)+b_{1}(\beta-\delta)\right]}{a^{\prime \prime}\left(a_{1} \alpha+b_{1} \beta\right)} \\
S=\frac{2 a_{1} b_{1}(\beta-\alpha)}{s_{1}\left[a_{1}(\alpha-\delta)+b_{1}(\beta-\delta)\right]} \\
U=\frac{b_{1}\left\{\left(a_{1}+b_{1}\right)\left[1+\left(t_{2}-t_{1}\right) \beta\right] \delta+a_{1}(\beta-\alpha)\right\}\left(a_{1} \alpha+b_{1} \beta\right)}{s_{1}\left[a_{1}(\alpha-\delta)+b_{1}(\beta-\delta)\right]^{2}}
\end{gathered}
$$

It should be noted that the denominator of $S$ is the same quantity as the numerator of $P$, and the denominator of $U$ is that quantity squared and multiplied by $s_{1}$. In the expression for $p$, eq 46 , the quantities $S / n$ and $4(n-1) U / n^{2}$ are small in comparison with unity, and the square root of the quantity in brackets, after numerical substitution, may be obtained conveniently by using only a few terms of the expansion

$$
(1 \pm \epsilon)^{\frac{1}{2}}=1 \pm \frac{\epsilon}{2}-\frac{\epsilon^{2}}{8} \pm \frac{\epsilon^{3}}{16} \ldots \ldots
$$

It should be noted, however, that the square root of the quantity in brackets in eq 46 is only slightly larger numerically than the negative 
quantity - $(1-S / n)$ to which it is to be added, and consequently these quantities must be correct to such a number of significant figures as will ensure that their small difference shall be sufficiently accurate. This small difference is multiplied by the large quantity $n P$ to obtain the value of $p$.

The use of even the simplified formulas, 46 to 50 , is so laborious as to justify some special comments. If the added range is greater than the original range by only a small factor, say 2 to 5 , these formulas are required, as in the case of a millivoltmeter with a basic range of 50 millivolts and an added range of 100 millivolts. Aside from such cases, however, the added range will usually be a relatively large multiple of the basic range; for example, 1.5 volts with a basic range of 50 millivolts. In this case $n=30$ and the values of $p$ for this and all higher ranges will not differ greatly from each other or from the value for $r_{v}=\infty$. For this last case the exact formula, eq 50a, in the following paragraph is very much less laborious, and it should ordinarily be used to determine a single tap point to serve for the 1.5volt and all higher ranges.

Two limiting values of $p$ are of interest. If $n=1, p=0$, as is evident from inspection of eq 46 . This condition is simply that of the original range as a millivoltmeter, and signifies (see fig. 13) that the tap point $T$ coincides with the point $D$. The other limiting case is that of $n=\infty$, for which

$$
\begin{aligned}
\underset{n=\infty}{p} & =P U \\
& =\frac{b_{1}\left\{\left(a_{1}+b_{1}\right)\left[1+\left(t_{2}-t_{1}\right) \beta\right] \delta+a_{1}(\beta-\alpha)\right\}}{a^{\prime \prime}\left[a_{1}(\alpha-\delta)+b_{1}(\beta-\delta)\right]}
\end{aligned}
$$

This is the value of $p$ which locates the tap point $T$ (fig. 13) from which a wire would be brought out to a binding post to provide a temperature-compensated milliampere range. Since the value of $p$ for $n=\infty$ is a limiting value which is asymptotically and closely approached by the usual volt ranges, and since this value of $p$ is the easiest one to compute, it should be computed first. If it is less than 1 , or even if it exceeds 1 by a small amount, it will be possible to provide volt ranges in the intended manner. If $p$ for $n=\infty$ materially exceeds 1 , only relatively low compensated volt ranges can be added.

It must not be inferred that in actual practice a separate tap point $T$ would be used for each volt range. This would complicate the construction and unduly increase the cost of the instrument. Instead, after computing $p$ for the desired ranges, the designer would choose a value intermediate between the extreme values, thus providing theoretically exact compensation only for some intermediate range. The ranges above this one would be slightly over-compensated, that is, the indication for a constant voltage would increase slightly with increasing temperature. Ranges below the chosen intermediate range would be slightly under-compensated. In an actual case, however, these defects of compensation may be so small as to be either impossible to detect or if just discernible they may be negligible in the practical use of the instrument. This matter may best be illustrated by a numerical example based on the millivoltmeter mechanism which formed the starting point for example 1 (see p. 512). 


\section{NUMERICAL EXAMPLES OF METHOD OF LOCATING THE VOLTMETER TAP POINT}

Example 2.-The values of $a_{1}{ }^{\prime}, \alpha^{\prime}, i_{f 1}, \delta, r_{1}, s_{1}, t_{1}$, and $t_{2}$ were as given in example 1 , but the value of total damping resistance $d_{1}$ was reduced to 6.56 ohms. This wes done because it was planned to bring out a voltmeter tap, and the reduction in $d_{1}$ would improve the damping when the instrument was used as a voltmeter. The use of eq 22 to 24 gave the following values:

Consequently:

$$
\begin{aligned}
& a_{1}=2.7426 \text { ohms. } \\
& b_{1}=7.2960 \text { ohms. } \\
& c_{1}=8.0067 \text { ohms. }
\end{aligned}
$$

$$
\begin{aligned}
a^{\prime \prime} & =a_{1}-1.564 \\
& =1.1786 \text { ohms. } \\
\alpha & =(1.564 \times 0.0034) / 2.7426 \\
& =0.00194 /{ }^{\circ} \mathrm{C} . \\
a_{2} & =2.7426+(1.564 \times 0.0034 \times 10) \\
& =2.7958 \text { ohms. }
\end{aligned}
$$

The value of $\gamma$ is taken as zero, hence $c_{2}=c_{1}=8.0067 \mathrm{ohms}$. Using eq 29, the value of $b_{2}$ is found to be $7.5364 \mathrm{ohms}$. Hence, by eq 30 ,

$$
\beta=\frac{7.5364-7.2960}{7.2960 \times 10}=0.00329
$$

The values of $p$ computed by eq 46 to 50 from the preceding data are as follows:

$$
\begin{array}{lrrrrrrrr}
n= & 30 & 100 & 300 & 1,000 & 3,000 & 10,000 & 30,000 & \infty \\
\text { Volts } & 1.5 & 5 & 15 & 50 & 150 & 500 & 1,500 & \infty
\end{array}
$$

$p=1.0031 \quad 1.02601 .0326 \quad 1.03491 .03551 .0358-1.03581 .0358+$

These values of $p$ are carried to more decimal places than would be used in practice, in order to show the very small change in $p$ for this large range of values of $n$.

In practice, it is impossible to have values of $p$ greater than unity. The value $p=1$ signifies that the tap point $T$ coincides witb the junction of the coils $a^{\prime}$ and $a^{\prime \prime}$. Before dismissing the above example as impractical, however, it should be assumed that the value $p=1$ will be used for all ranges, and the extent of the departure from compensation should be computed. Before this can be done, it is necessary to find the value of $r_{n}$, the resistance of the higher range, and of $\boldsymbol{c}_{n}$ (see fig. 13).

The resistance of the higher range at reference temperature is

$$
r_{n 1}=\frac{n e_{f}}{i_{n 1}}=\frac{n e_{f}}{\frac{i_{1}\left(a_{1}+b_{1}\right)}{\left(p a^{\prime \prime}+b_{1}\right)}}=\frac{n e_{f}\left(p a^{\prime \prime}+b_{1}\right)}{i_{1}\left(a_{1}+b_{1}\right)}
$$

The resistance of the part of the higher range which is composed of $a_{1}^{\prime}+(1-p) a^{\prime \prime}$ in parallel with $p a^{\prime \prime}+b_{1}$ is

$$
r_{n 1}-c_{n 1}=\frac{\left[a_{1}^{\prime}+(1-p) a^{\prime \prime}\right]\left(p a^{\prime \prime}+b_{1}\right)}{a_{1}+b_{1}}
$$


and consequently

$$
c_{n 1}=\frac{n e_{f}\left(p a^{\prime \prime}+b_{1}\right)}{i_{1}\left(a_{1}+b_{1}\right)}-\frac{\left[a_{1}^{\prime}+(1-p) a^{\prime \prime}\right]\left(p a^{\prime \prime}+b_{1}\right)}{a_{1}+b_{1}}
$$

After the value of $r_{n 1}$ has been computed for one range, with a given value of $p$, values of $r_{n 1}$ for the higher ranges will be in proportion to their full-scale voltages. Also, the second term on the right in eq 53 need be computed only once, as far as values at reference temperature are concerned. Its value should be computed for the higher temperature $t_{2}$ also. It is convenient to assume that the $c$ coils are to be of manganin of negligibly small temperature coefficient.

The use of these formulas in the case of example 2 with $p$ taken as equal to 1 for all ranges, gives the following results:

At reference temperature, $20^{\circ} \mathrm{C}$, the calculated values are

$$
\begin{aligned}
r_{n 1}-c_{n 1} & =1.3203 \text { ohms. } \\
r_{n 1}, \text { for } n & =30,=348.46 \text { ohms. } \\
c_{n 1}, \text { for } n & =30,=347.14 \text { ohms. }
\end{aligned}
$$

The values of $r_{n 1}$ for higher values of $n$ will be in direct proportion to $n$, for example,

$$
\begin{aligned}
& \begin{array}{lllll}
n=30 & 100 & 300 & 1,000 & 3,000
\end{array} \\
& n e_{f}=\begin{array}{lllll}
1.5 & 5 & 15 & 50 & 150 \text { volts }
\end{array} \\
& r_{n 1}=348.46 \quad 1,161.5 \quad 3,484.6 \quad 11,615 \quad 34,846 \mathrm{ohms}
\end{aligned}
$$

At the higher temperature $t_{2}=30^{\circ} \mathrm{C}, r_{n 2}-c_{n 2}$ will be $1.3640 \mathrm{ohms}$, that is, it will be $0.0437 \mathrm{ohm}$ greater than $r_{n 1}-c_{n 1}$. On the assumption that the values of $c_{n}$ are invariable with temperature, each of the values of $r_{n 2}$ will be $0.0437 \mathrm{ohm}$ greater than the corresponding $r_{n 1}$. The values of the current $i_{n}$ in the branch $c_{n}$ produced by fullscale voltage $n e_{f}$ will thus be slightly less at $30^{\circ}$ than at $20^{\circ}$. The defect in the compensation for any range may be computed in a way which will be illustrated by applying it to the extreme ranges, namely, the 1.5- and 150-volt ranges. In order to demonstrate the exactness of the formulas and the high degree of compensation which can theoretically be obtained by their use, many of the values in this and in subsequent numerical examples are carried to a greater number of significant figures than would be warranted by the possible precision of reading the indication of the instrument.

For the 1.5-volt range,

$$
i_{n 2} \text { at } 30^{\circ} \mathrm{C}=1.5 / 348.5037=0.004,304,1 \text { ampere }
$$

Of this current, the part $i_{2}$ in the moving coil is

$$
\begin{aligned}
\frac{\left(a^{\prime \prime}+b_{2}\right) i_{n 2}}{a_{2}+b_{2}} & =\frac{8.7150 \times 0.004,304,1}{2.7958+7.5364} \\
& =0.003,630,42 \text { ampere }
\end{aligned}
$$

At $30^{\circ} \mathrm{C}$ the current in the moving coil to produce full-scale deflection, with $\delta$ taken into account, is $0.003,634 / 1.001=0.003,630,37$ ampere. The discrepancy is thus $0.000,000,05$ ampere, which is 1 part in 70,000 , which is equivalent to about 0.002 division in a deflection of 150 divisions. An error in compensation ten times as great as this could hardly be detected by the most careful observer. It is 
thus entirely permissible to use the round value $p=1$ for the 1.5 -volt range.

For the 150-volt range,

$$
i_{n 2} \text { at } 30^{\circ}=150 / 34,846=0.004,304,7 \text { ampere }
$$

Of this current the part through the moving coil is

$$
\frac{8.7150 \times 0.004,304,7}{10.3322}=0.003,630,9 \text { ampere }
$$

The current should be $0.003,630,4$ ampere. The actual current will be too large by $0.000,000,5$ ampere, that is, it is too large by 1 part in 7,200 , which is equivalent to about 0.02 division in a deflection of 150 divisions. This discrepancy in the current is in the direction opposite to the discrepancy for the 1.5-volt range, and is negligibly small. Similar calculations show that the round value $p=1$ can be used for all ranges above 1.5 volts without discernible error.

If the computed values of $p$ had exceeded 1 by an amount so large that the use of $p=1$ would have resulted in objectionable defects in the temperature compensation of the higher ranges, it would have been necessary to revise the requirements to bring $p$ down to a practical value. It is not possible to increase $s$ without making some structural change in the mechanism, and it is usually desirable to hold $r$ at a standard value. This leaves $d$ as the most eligible quantity to be revised, because the requirements as to damping are not rigid. To exhibit the effect on $p$ of a change in $d$, the next example will differ from example 2 only in that $d$ is increased.

Example 3.-Let $s_{1}=13.759$ ohms, $r_{1}=10 \mathrm{ohms}, d_{1}=7$ ohms. These values, substituted in eq 22 to 24 , give the following values:

Also,

$$
\begin{aligned}
& a_{1}=3.0345 \text { ohms. } \\
& b_{1}=8.0725 \text { ohms. } \\
& c_{1}=7.7946 \text { ohms. }
\end{aligned}
$$

$$
\begin{aligned}
\alpha & =(1.564 \times 0.0034) / 3.0345=0.00175 \\
a^{\prime \prime} & =3.0345-1.564=1.4705 \text { ohms. } \\
a_{2} & =3.0345+(1.564 \times 0.034) \\
& =3.0877 \text { ohms. }
\end{aligned}
$$

With $t_{2}-\mathrm{t}_{1}=10^{\circ}, \delta=0.0001$, and $c_{2}=c_{1}=7.7946 \mathrm{ohms}$, the use of eq 29 gives

$$
b_{2}=8.3259 \mathrm{ohms} \text {. }
$$

The use of this value in eq 30 gives

$$
\beta=0.00314 .
$$

Values of $p$ computed by eq 46 to 50 are as follows:

$$
\begin{array}{ll}
n=30 & (1.5 \text {-volt range) } \\
n=\infty & p=0.9652 . \\
p=0.9965 .
\end{array}
$$


Comparison of these values of $p$ with those of example 2 shows that if $d_{1}$ were given the value $6.78 \mathrm{ohms}$ (the mean of the values of $d_{1}$ in examples 2 and 3 ) the values of $n$ for the above two limiting cases would probably be about $1-0.016$ and $1+0.016$, respectively. This may be considered as the ideal case, for the defect in the compensation, with one compromise value of $p(=1)$ for all ranges, will have negligibly small values for the extreme values of $n$ and still smaller values for intermediate values of $n$. It is easily shown, however, that even for $d=7$ and the resulting values of $p$ the defect in compensation will be negligible for the 1.5 -volt and all higher ranges. The computed values of defect in compensation are 0.015 percent for $n=30$ and 0.002 percent for $n=\infty$.

\section{METHOD FOR OBTAINING A ROUND VALUE OF OHMS PER VOLT IN THE VOLT RANGES}

Instead of stating the current required by a voltmeter for full-scale deflection, American makers usually express the sensitivity of the voltmeter by stating the reciprocal of this current, which is given as so many "ohms per volt." Its value is found by dividing the resistance of any range of the voltmeter by the full-scale voltage for this range.

It has been shown in the preceding section that if a Swinburnecompensated millivoltmeter be provided with a tap on the $a^{\prime \prime}$ coil for a higher range, the value of ohms per volt for this higher range will be greater than for the original millivolt range. Furthermore, even in millivoltmeters which are nominally identical and are adjusted to identical values of resistance and of millivolts for full-scale deflection, the values of ohms per volt, for a given higher range, will not be identical because of variations in spring strength and magnet strength of individual instruments. It is good practice to have a round and standardized value of ohms per volt for the millivolt range, and it is even more desirable for the volt range (or ranges) because such standardization permits the use of interchangeable multipliers with standardized round values of resistance in their various sections. If the millivoltmeter has a round value of ohms per volt, it will usually be advisable to adopt the same value of ohms per volt for the added volt ranges. An excessive reduction of the ohms per volt of the volt ranges is not advisable if it can be avoided.

A method for bringing the added higher range down to a desired value of ohms per volt has been used for many years by a prominent German manufacturer, but no description of the method has been published, so far as the author of this paper is aware. It will be described with reference to figure 14 , which shows the network of figure 13 , plus an added branch of resistance $m$. This new branch is in parallel with a current path composed of the moving coil $a^{\prime}$, the part $(1-p) a^{\prime \prime}$ of the manganin coil $a^{\prime \prime}$, and the part $v$ of the series resistor $c_{n}$ for the higher range. A part of the current taken by the voltmeter is diverted around the moving coil by the coil $m$. The effect is similar to that which would result from a reduction in the sensitivity because of a weakening of the magnet or an increase in the strength of the springs. If the coil $c_{n}$ had the correct value before the application of the coil $m$, it will be necessary, after applying $m$, to cut out of circuit a part of $c_{n}$ as is done (fig. 14) by bringing out a tap from the point $T^{\prime \prime}$ on $c_{n}$ to the binding post $V^{\prime}$, in order that the 
specified voltage shall produce full-scale deflection. The small portion of $c_{n}$ to the right of $T^{\prime \prime}$ and the terminal $V$ are then to be discarded. The problem is to find suitable values of $m, v$, and $w$ which will give the desired round value of ohms per volt for the range having the terminals $A$ and $V^{\prime}$. There is no unique solution. The desired value of ohms per volt may be obtained by the use of any one of an infinite number of values of $m$ with corresponding values of $v$ and $w$. Because an arbitrary choice of $m$ must be made, and also because the analysis would probably become very involved, it has not seemed desirable to develop a general expression for the network of figure 14 with which to determine by a single solution the values of all the branches in such a way as to provide the basic range as a millivoltmeter and the higher range, of a definite number of ohms per volt, with temperature compensation for each range. Instead, it seems much better first to

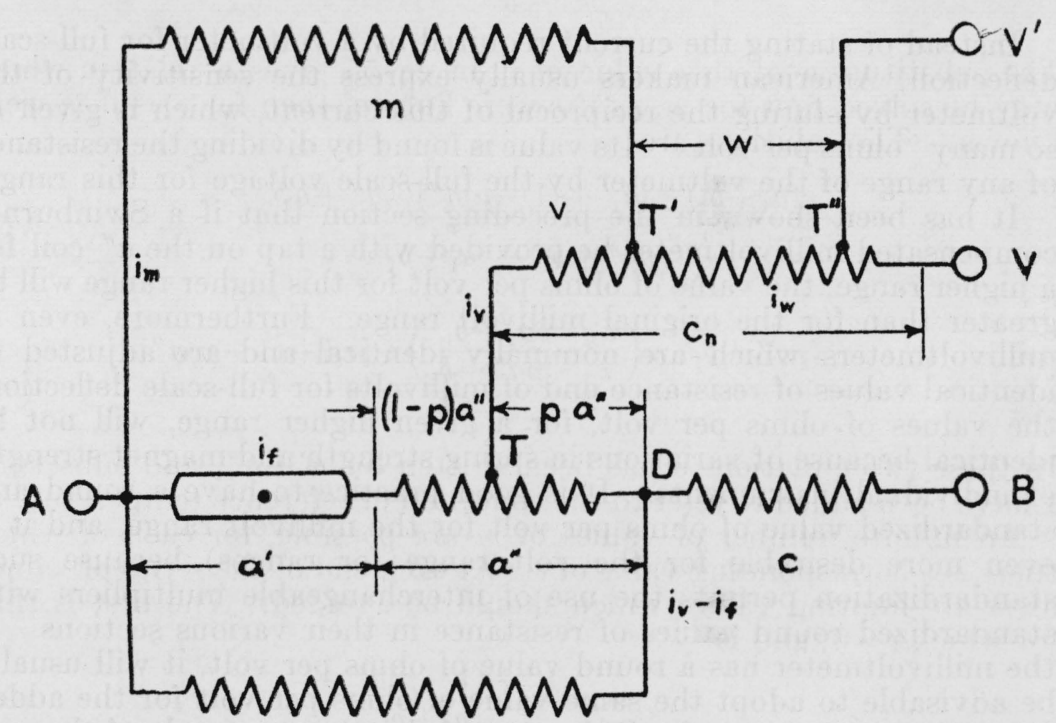

Figure 14.-Swinburne-compensated millivoltmeter in which an added volt range originally consisting of a coil $c_{n}$ joining the tap point $T$ to a terminal $V$ has been given a desired round value of ohms per volt by the addition of the coil $m$ and the terminal $V^{\prime}$ connected to the tap point $T^{\prime \prime}$.

determine the values of $a, b, c$, and $\beta$ to satisfy the requirements for the millivolt range; then to compute values of $p$ for the higher ranges and to choose a suitable compromise value of $p$ which minimizes the defects of compensation of the higher ranges; then to compute $c_{n}$ for the lowest volt range, as if no shunt coil $m$ would be used. These steps having been taken, it becomes necessary to take account of the coil $m$.

Referring to figure 14 , let it be assumed that the volt range having the terminals $A$ and $V^{\prime}$ has the desired value $y$ of ohms per volt, the reciprocal of which value is the current $i_{w}$ in the branch $w$ for full-scale deflection. This current divides at the point $T^{\prime}$ into a current $i_{m}$ through $m$ and a current $i_{0}$ through $v$. The current $i_{v}$ divides at $T$ into two parts, one of which is the current $i_{f}$ in the moving coil for full-scale deffection. 
The current in $v$ is

$$
i_{v}=\frac{\left(a^{\prime}+a^{\prime \prime}+b\right) i_{f}}{p a^{\prime \prime}+b}
$$

The potential difference between the points $A$ and $T^{\prime}$ is

$$
\begin{aligned}
m i_{m} & =v i_{o}+\left[a^{\prime}+(1-p) a^{\prime \prime}\right] i_{f} \\
& =\frac{v\left(a^{\prime}+a^{\prime \prime}+b\right) i_{f}}{p a^{\prime \prime}+b}+\left[a^{\prime}+(1-p) a^{\prime \prime}\right] i_{f}
\end{aligned}
$$

Also,

$$
\begin{aligned}
i_{m} & =i_{w}-i_{o} \\
& =i_{w}-\frac{\left(a^{\prime}+a^{\prime \prime}+b\right) i_{f}}{p a^{\prime \prime}+b}
\end{aligned}
$$

The substitution of this value of $i_{m}$ in eq 55 gives a relation which may be solved first for $m$, as if $v$ were known, then for $v$ as if $m$ were known. The solutions are

$$
\begin{aligned}
& m=\frac{v\left(a_{1}+b_{1}\right)+\left[a_{1}{ }^{\prime}+(1-p) a^{\prime \prime}\right]\left(p a^{\prime \prime}+b_{1}\right)}{\frac{i_{w 1}}{i_{f 1}}\left(p a^{\prime \prime}+b_{1}\right)-\left(a_{1}+b_{1}\right)} \\
& v=\frac{\left(p a^{\prime \prime}+b_{1}\right)\left\{m\left(\frac{i_{w 1}}{i_{f 1}}-\frac{a_{1}+b_{1}}{p a^{\prime \prime}+b_{1}}\right)-\left[a_{1}{ }^{\prime}+(1-p) a^{\prime \prime}\right]\right\}}{a_{1}+b_{1}}
\end{aligned}
$$

In these two equations $a$ has been written for $a^{\prime}+a^{\prime \prime}$, and subscripts 1 have been added to refer to the condition of reference temperature $t_{1}$.

An infinite number of values of $m$ are possible, for each of which there is a corresponding value of $v$. At each end of the series of values of $m$ are limiting values which should be avoided. The first is that for which $v=0$, and is

$$
m_{v=0}=\frac{a_{1}{ }^{\prime}+(1-p) a^{\prime \prime}}{\frac{i_{i v}}{i_{f}}-\frac{a_{1}+b_{1}}{p a^{\prime \prime}+b_{1}}}
$$

This value of $m$ will be relatively low. The addition of this coil to the network will cause the maximum disturbance in the performance of the instrument as a millivoltmeter, and will consequently require a greater revision of the original values of $a, b, c$, and $\beta$. A further probable disadvantage is that this low value of $m$ may cause overdamping. There is no compensating advantage in using it and it may be dismissed from further consideration.

The other limiting value of $m$ is that for which the coil $m$ is connected between the points $A$ and $V$. The current taken by $m$ has then little effect on the performance of the instrument, other than to make it take more current than it would if $m$ were absent. In other words, the coil $m$ is merely a little additional load on the source whose voltage is being measured. This case has the advantage of producing the minimum disturbance of the damping and of the performance of the instrument as a millivoltmeter but it has an objectionable feature which should exclude it from use. If the coil $m$, connected 
between the points $A$ and $V$, should become open-circuited, the performance as a voltmeter with these points as terminals would be unaffected and the defect would not be revealed by a check of this range. All higher ranges, however, would be in error. This limiting value of $m$ is given by the formula

$$
\underset{v=c_{\mathrm{n}}}{m}=\frac{r_{n} y_{n} e_{f}}{r_{n}-y n e_{f}}
$$

in which $r_{n}$ is the resistance of the volt range with terminals $A$ and $V$, the coil $m$ not having been applied; $n e_{f}$ is the full-scale value of voltage for this range, and $y$ is the desired number of ohms per volt.

In the choice of an intermediate value of $m$ the following suggestions may be useful. First, $m$ should have several hundred times the resistance of the moving coil $a^{\prime}$ plus the part $(1-p)$ of the coil $a^{\prime \prime}$, in order that the addition of $m$ may produce only a very small effect on the performance of the instrument as a millivoltmeter. The value of $m$ should not be so high, however, as to make $w$ small in comparison with $v$. If the voltage range which has $A$ and $V^{\prime}$ as terminals is of only a few volts, a satisfactory value of $m$ may be one which makes $v$ and $w$ approximately equal. If this range, however, is of say 10 or 15 volts, the value of $m$ for $v=w$ may be needlessly high, and it would be better to take a round value of $m$ of, say $1,000 \mathrm{ohms}$, and let $v$ be relatively small in comparison with $w$. In the search for a suitable value of $m$ eq 58 may be used with trial values assumed for $v$, beginning with $v=c_{n} / 2$. The values of $m$ having been plotted as a function of $v$, inspection of the curve will facilitate the choice of a round value of $m$ (in general, a multiple of $100 \mathrm{ohms}$ ) for which $v$ is not much greater than $c_{n} / 2$. Then the chosen value of $m$ may be substituted in eq 59 to obtain the exact value of $v$.

The next step is to determine the value of $w$. Referring to figure 14 , the resistance between the points $A$ and $V^{\prime}$ may be put equal to the full-scale voltage, ne, either divided by the current $i_{w}$ which the voltmeter range is to require for full-scale deflection, or (what is the same thing) multiplied by $y$, the required number of ohms per volt. The resistance $w$ will be equal to this total resistance, yne, minus the resultant resistance of the network between the points $T^{\prime}$ and $A$; that is, for the condition of reference temperature $t_{1}$,

$$
\begin{aligned}
& w=y n e-\frac{m\left\{v+\frac{\left[a_{1}{ }^{\prime}+(1-p) a^{\prime \prime}\right]\left(p a^{\prime \prime}+b_{1}\right)}{a_{1}{ }^{\prime}+a^{\prime \prime}+b_{1}}\right\}}{m+v+\frac{\left[a_{1}{ }^{\prime}+(1-p) a^{\prime \prime}\right]\left(p a^{\prime \prime}+b_{1}\right)}{a_{1}{ }^{\prime}+a^{\prime \prime}+b_{1}}} \\
& =y n e-\frac{m\left\{v\left(a_{1}+b_{1}\right)+\left[a_{1}{ }^{\prime}+(1-p) a^{\prime \prime}\right]\left(p a^{\prime \prime}+b_{1}\right)\right\}}{(m+v)\left(a_{1}+b_{1}\right)+\left[a_{1}{ }^{\prime}+(1-p) a^{\prime \prime}\right]\left(p a^{\prime \prime}+b_{1}\right)}
\end{aligned}
$$

The next step is to take care of the fact that the indications of the instrument, used as a millivoltmeter, will now be too low because of the diversion of part of the current away from the moving coil. In general, it would be necessary to revise the values of $a_{1}, b_{1}$, $c$, and $\beta$ to take account of this added current patb. Then a revised value of $p$ would have to be computed, as well as revised values of $v$ and $w$ for the chosen $m$, which could remain unchanged. Theoretically, 
these changes would cause a slight change in the accuracy of the millivoltmeter, and the values of $a_{1}, b_{1}, c$, and $\beta$ would need another (though much smaller) readjustment, which would in turn call for revision of the values of $p, v$, and $w$, and so on. Such a process of repeated readjustment would be laborious, but a special expedient has been found which makes it unnecessary.

It may be seen from figure 14 that any change in the resistance of the coil $c$ will have no effect on the added volt range, and also that any necessary readjustments of $p a^{\prime \prime}$ and of $b_{1}$ will have no effect on the volt range if the sum of these two resistances is kept unchanged. These latter readjustments are equivalent to sliding the junction point $D$ along $p a^{\prime \prime}+b_{1}$, and with a suitable change in $c$ they provide the means for readjusting the accuracy of the millivolt range without any reaction on the accuracy of the volt range at reference temperature. In determining the original $v$ alues of $a_{1}, b_{1}$, and $c_{1}$ for the millivolt range, eq 22 to 24 were used. These equations express three conditions to be satisfied, namely, prescribed values of sensitivity resistance $s_{1}$, millivoltmeter resistance $r_{1}$, and total damping resistance $d_{1}$. One of these requirements must now give way to make room for the condition that $p a^{\prime \prime}$ and $b_{1}$ are to change as may be necessary while their sum is to remain constant. The sensitivity of the mechanism, which determines $s_{1}$, is not to be changed, and it is desirable that $r_{1}$ should retain its original value. This leaves $d_{1}$ as the quantity which can best undergo any small change which will result from the revision of the initial values of $a_{1}, b_{1}$, and $c_{1}$.

Referring to figure 14, let the network consisting of $a^{\prime}+(1-p) a^{\prime \prime}$ shunted by $v+m$ be regarded as an equivalent moving coil with terminals at $A$ and $T$. Its resistance at temperature $t_{1}$ is

$$
a_{e q 1}^{\prime}=\frac{\left[a_{1}{ }^{\prime}+(1-p) a^{\prime \prime}\right](m+v)}{a_{1}{ }^{\prime}+(1-p) a^{\prime \prime}+m+v}
$$

On the preferable assumption that $a^{\prime \prime}, m$, and $v$ have zero temperature coefficient of resistance, the resistance of the equivalent moving coil at temperature $t_{2}$ is

$$
a_{e y 2}^{\prime}=\frac{\left[a_{2}^{\prime}+(1-p) a^{\prime \prime}\right](m+v)}{a_{2}^{\prime}+(1-p) a^{\prime \prime}+m+v}
$$

The temperature coefficient of resistance of the equivalent moving coil, assumed as linear over the temperature range $t_{1}$ to $t_{2}$, is

$$
\alpha^{\prime}{ }_{e q}=\frac{a_{e q 2}^{\prime}-a^{\prime}{ }_{e q 1}}{a_{e q 1}^{\prime}\left(t_{2}-t_{1}\right)}
$$

The current in the equivalent moving coil for full-scale deflection $\theta_{1}$ at temperature $t_{1}$ is

$$
\left(i_{f}\right)_{e q 1}=\frac{\left[a_{1}{ }^{\prime}+(1-p) a^{\prime \prime}+m+v\right] i_{\Omega}}{m+v}
$$


where $i_{f 1}$ is the current in the actual moving coil. From eq 66, for full-scale deflection $\theta_{1}$,

$$
i_{f_{1}}=\frac{m+v}{a_{1}^{\prime}+(1-p) a^{\prime \prime}+m+v} \cdot\left(i_{f}\right)_{e q 1}
$$

If the current in the equivalent moving coil be kept at the value $\left.i_{f}\right)_{e q 1}$ and the temperature be raised to $t_{2}, a_{1}^{\prime}$ in eq 66 will become $a_{2}^{\prime}$ and the current in the actual moving coil will decrease accordingly. Its value becomes

$$
i_{2}=\frac{m+v}{a_{2}^{\prime}+(1-p) a^{\prime \prime}+m+v} \cdot\left(i_{f}\right)_{e q 1}
$$

This reduction in $i$ tends to make the deflection $\theta_{2}$, at temperature $t_{2}$, lower than $\theta_{1}$. This tendency, however, is opposed by the action of the temperature increase on the magnet and springs, of which $\delta$ is the measure. The ratio of the deflection at the higher temperature $t_{2}$ to the deflection at reference temperature $t_{1}$ will be

$$
\frac{\theta_{2}}{\theta_{1}}=\frac{a_{1}^{\prime}+(1-p) a^{\prime \prime}+m+v}{a_{2}^{\prime}+(1-p) a^{\prime \prime}+m+v} \cdot\left[1+\left(t_{2}-t_{1}\right) \delta\right]
$$

and the temperature coefficient of the deflection, for the equivalent moving coil, is

$$
\delta_{e q}=\frac{\frac{\theta_{2}}{\theta_{1}}-1}{t_{2}-t_{1}}
$$

The "sensitivity resistance" of the equivalent moving coil at reference temperature $t_{1}$ is, by eq 15 and 16 ,

$$
s_{e q 1}=\frac{e_{f}}{\left(i_{f}\right)_{e q 1}}=\frac{e_{f}(m+v)}{\left[a_{1}^{\prime}+(1-p) a^{\prime \prime}+m+v\right] i_{f 1}}
$$

The resistance $a_{e q 1}^{\prime}$, temperature coefficient of resistance $\alpha^{\prime}{ }_{e q}$, temperature coefficient of deflection $\delta_{e q}$, and sensitivity resistance $s_{e q 1}$ having been determined by eq $63,65,70$, and 71 , the problem is now to determine, on the basis of the equivalent moving coil, revised values $a_{r}, b_{r}$, and $c_{r}$ to satisfy two of the previous requirements for the millivolt range, namely, a prescribed full-scale potential difference $e_{f}$ and a prescribed resistance $r$ of the millivoltmeter. These two requirements are expressed in forms identical with those of eq 17 and 19 , and are

$$
\begin{gathered}
a_{r 1} b_{r 1}+a_{r 1} c_{r 1}+b_{r 1} c_{r 1}-b_{r 1} s_{c q 1}=0 \\
a_{r 1} b_{r 1}+a_{r 1} c_{r 1}+b_{r 1} c_{r 1}-a_{r 1} r_{1}-b_{r 1} r_{1}=0
\end{gathered}
$$

in which the additional subscripts 1 denote the values at reference temperature $t_{1}$.

The third equation, which expresses the new requirement that the sum of $p a^{\prime \prime}$ and $b$ is to remain constant, and which displaces equation 21 concerning the damping, may be written

$$
a_{r 1}+b_{r 1}-a^{\prime}{ }_{e 1}-b_{1}-p a^{\prime \prime}=0
$$


The solution of these three equations gives the following results:

$$
\begin{aligned}
a_{r 1} & =\frac{\left(a_{e q 1}^{\prime}+p a^{\prime \prime}+b_{1}\right)\left(s_{e q 1}-r_{1}\right)}{s_{e q 1}} \\
b_{r 1} & =\frac{\left(a_{e q 1}^{\prime}+p a^{\prime \prime}+b_{1}\right) r_{1}}{s_{e q 1}} \\
c_{r 1} & =r_{1}\left[1-\frac{\left(a_{e q 1}^{\prime}+p a^{\prime \prime}+b_{1}\right)\left(s_{e q 1}-r_{1}\right)}{s_{e q 1}^{2}}\right]
\end{aligned}
$$

Values of these three branches at reference temperature $t_{1}$, computed by these formulas, will make the indication of the millivoltmeter and its resistance correct at reference temperature. In order that it may be compensated for temperature, a revised value $\beta_{r}$ of $\beta$ is required.

In the revised millivoltmeter network the coil $c_{r}$ is to be of manganin and the portion $p a^{\prime \prime}$ of the original network is to be replaced by a manganin coil having a resistance

$$
a_{r}^{\prime \prime}=a_{r 1}-a_{e q 1}^{\prime}
$$

The resistance at temperature $t_{2}$ of the new branch $a_{r}$ will be

$$
a_{r 2}=a_{e q 2}^{\prime}+a_{r}^{\prime \prime}
$$

In order that the deflection as a millivoltmeter shall be the same at temperatures $t_{2}$ and $t_{1}$ it is necessary (see eq 29) that

Then

$$
b_{r 2}=\frac{a_{r 2} c_{r 2}}{s_{e q 1}\left[1+\left(t_{2}-t_{1}\right) \delta_{r}\right]-a_{r 2}-c_{r 2}}
$$

$$
\beta_{r}=\frac{b_{r 2}-b_{r 1}}{b_{r 1}\left(t_{2}-t_{1}\right)}
$$

If $m$ has been chosen sufficiently large with respect to $a^{\prime}+(1-p) a^{\prime \prime}$ the increment of resistance per degree, $b_{r 1} \beta_{r}$, will differ only slightly from the original value $b_{1} \beta$, and the temperature compensation of the voltmeter range (or ranges) will be only slightly changed. If the change is larger than is desired, a slight change may be made in $\beta$ in order to divide the error of compensation between the volt ranges and the millivolt range.

The method above outlined for bringing the sensitivity of the added volt range down to a round value of ohms per volt was applied to the voltmeter-millivoltmeter developed in example 2, as outlined in the following example.

\section{NUMERICAL EXAMPLE OF THE METHOD FOR OBTAINING A ROUND VALUE OF OHMS PER VOLT}

Example 4.-This is the case of example 2 (p. 527) with $p$ taken equal to 1 for all ranges from 1.5 volts up, and with the additional requirement that the sensitivity of all of these volt ranges should be 
$200 \mathrm{ohms}$ per volt. The network ${ }^{22}$ for example 2, with numerical values of resistance indicated, is shown in figure 15 . The additional coil $m$ to be supplied, and subdivisions $v$ and $w$ of the coil $c_{n}$ are indicated. It is the object of this problem to determine values of $m, v, w$, and the revised values of $a_{1}, b_{1}, c$, and $\beta$ to give the volt ranges a sensitivity of $200 \mathrm{ohms}$ per volt. The coil $c_{n}$ and the terminal marked " 1.5 volts, $232 \mathrm{ohms}$ per volt" apply to the case of example 2 for which $m$ may be regarded as infinite, for which case $v+w=c_{n}$.

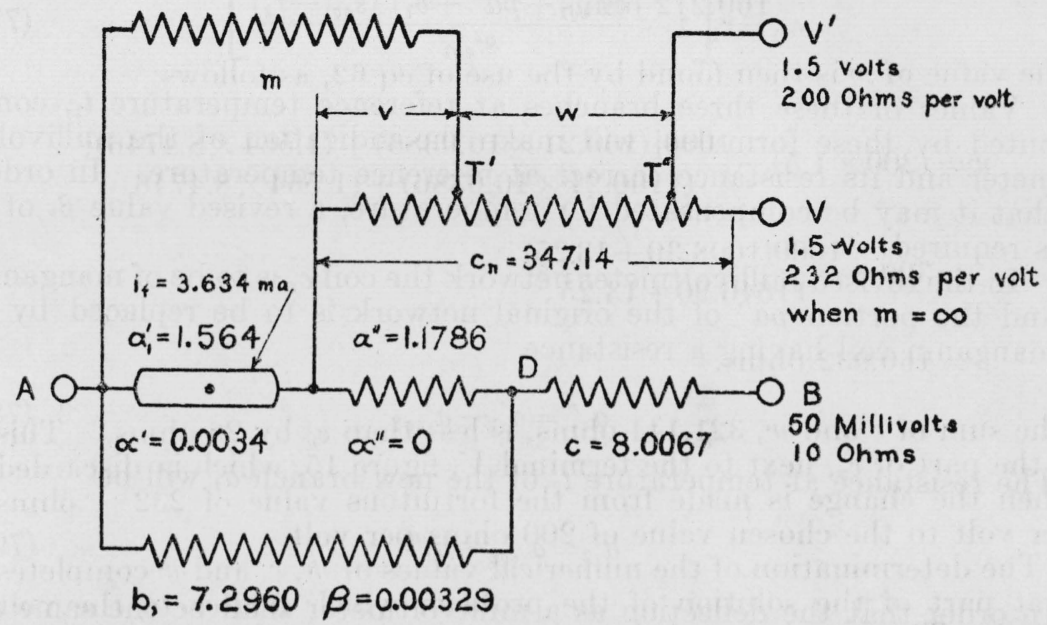

FIGURE 15.-Swinburne-compensated millivoltmeter with an added volt range, the sensitivity of which is to be brought down from its original random value? 232 ohms per volt to the round value $200 \mathrm{ohms}$ per volt, by the addition of the coil $\mathrm{m}$.

The numerical values shown apply to the case of the random value of ohms per volt. After the application of $m$, the values of $a^{*}, b_{1}$, and $c$ become 1.1702, 7.3044, and $8.0116 \mathrm{ohms}$, respectively.

The limiting values of $m$, which are to be avoided, are by eq 60 and 61

$$
\begin{aligned}
m_{v=0} & =\frac{1.564+0}{\frac{0.005}{0.003634}-\frac{2.7426+7.2960}{8.4746}} \\
& =\frac{1.564}{0.1913}=8.176 \mathrm{ohms} . \\
m_{v=c_{n}} & =\frac{300 \times 348.46}{348.46-300}=2,157 \mathrm{ohms} .
\end{aligned}
$$

The value of $m$ for $v=c_{n} / 2$, by eq. 58 , is

$$
\begin{aligned}
{\underset{v i c}{n / 2}}_{n} & =\frac{(173.57 \times 10.0386)+}{\left.\frac{0.005 \times 8.4746}{0.003634}-1.564 \times 8.4746\right)}-10.0386 \\
& =\frac{1755.65}{1.6217}=1,082.6 \mathrm{ohms} .
\end{aligned}
$$

22 It is slightly unfortunate, for the purposes of this example, that $p=1$. The method of computing the revised values of resistance of the coils $a, b$, and $c$, however, when $p$ is not equal to 1 canlibe readily understood. The fact that $p=1$ simplifies the construction by avoiding the necessity for one coil.

$89799-36-4$ 
Since this odd value of $m$ is associated with an odd value of $v$, it will be convenient to give $m$ the desirable even value, 1,000 ohms. The corresponding value of $v$, by eq 59 , is

$$
\begin{aligned}
\underset{m=1,900}{v} & =\frac{8.4746\left\{1000\left(\frac{0.005}{0.003634}-\frac{10.0386}{8.4746}\right)-1.564\right\}}{10.0386} \\
& =160.212 \mathrm{ohms} .
\end{aligned}
$$

The value of $w$ is then found by the use of eq 62 , as follows:

$$
\begin{aligned}
w & =(200 \times 1.5)-\frac{1000[(160.21 \times 10.0386)+(1.564 \times 8.4746)]}{(1160.21 \times 10.0386)+(1.564 \times 8.4746)} \\
& =300-\frac{1000(1608.30+13.25)}{11646.90+13.25} \\
& =160.932 \mathrm{ohms} .
\end{aligned}
$$

The sum of $v$ and $w, 321.144 \mathrm{ohms}$, is less than $c_{n}$ by $26 \mathrm{ohms}$. This is the part of $c_{n}$, next to the terminal $V$, figure 15 , which is discarded when the change is made from the fortuitous value of $232+$ ohms per volt to the chosen value of $200 \mathrm{ohms}$ per volt.

The determination of the numerical values of $m, v$, and $w$ completes that part of the solution of the problem which relates to the volt range. The remainder of the solution consists of the determination of revised values $a_{r}, b_{r}$, and $c_{r}$ which will restore the accuracy and the temperature compensation of the millivolt range.

By eq 63 , the resistance of the equivalent moving coil at temperature $t_{1}$ is

$$
a_{e q 1}^{\prime}=\frac{1.564 \times 1160.212}{1.564+1160.212}=1.5619 \mathrm{ohms} .
$$

At temperature $t_{2}$,

$$
a_{\text {eq2 }}^{\prime}=\frac{1.617176 \times 1160.212}{1161.829}=1.6149 \mathrm{ohms} .
$$

Consequently, by eq 65 ,

$$
\alpha^{\prime}{ }_{e q}=\frac{1.6149-1.5619}{1.5619 \times 10}=0.00339 /{ }^{\circ} \mathrm{C} .
$$

By eq 66 ,

$$
\begin{aligned}
\left(i_{f}\right)_{e q 1} & =\frac{(1.564+1160.212) \times 0.003634}{1160.212} \\
& =0.0036389 \text { ampere }
\end{aligned}
$$


By eq 69, the ratio of the deflection $\theta_{2}$ at temperature $t_{2}$ to the deflection $\theta_{1}$ at temperature $t_{1}$, the current in the equivalent moving coil being the same in the two cases, is

$$
\begin{aligned}
\frac{\theta_{2}}{\theta_{1}} & =\frac{1.564+1160.21}{1.617176+1160.21} \times 1.001 \\
& =1.000954
\end{aligned}
$$

from which, by eq 70 ,

By eq 71,

$$
\delta_{e q}=0.000095
$$

$$
\begin{aligned}
s_{\text {eq1 }} & =\frac{0.050 \times 1160.212}{(1.564+1160.212) \times 0.003634} \\
& =13.7404 \mathrm{ohms} .
\end{aligned}
$$

Then the revised values of the $a, b$, and $c$ branches at reference temperature $t_{1}$, by eq 75 to 77 , must be

$$
\begin{aligned}
a_{r 1} & =\frac{(1.5619+1.1786+7.2960) \times 3.7404}{13.7404} \\
& =2.7321 \mathrm{ohms} . \\
b_{r 1} & =\frac{(1.5619+1.1786+7.2960) \times 10}{13.7404} \\
& =7.3044 \mathrm{ohms} . \\
c_{r 1} & =10\left[1-\frac{(1.5619+1.1786+7.2960) \times 3.7404}{(13.7404)^{2}}\right] \\
& =10(1-0.19884) \\
& =8.0116 \mathrm{ohms} .
\end{aligned}
$$

In the revision of the millivoltmeter network the portion $p a^{\prime \prime}$ of the original network, having a resistance of $1.1786 \mathrm{ohms}$, is to have a resistance

$$
\begin{aligned}
a_{r}^{\prime \prime} & =a_{r 1}-a_{\text {eq1 }}^{\prime}=2.7321-1.5619 \\
& =1.1702 \mathrm{ohms} .
\end{aligned}
$$

This coil is to be of manganin. The sum of the resistances $a_{r}^{\prime \prime}$ and $b_{r}$, $1.1702+7.3044$, equals the sum of the corresponding values before revision, namely, $1.1786+7.2960$.

The resistance at temperature $t_{2}\left(=30^{\circ} \mathrm{C}\right)$ of the revised branch $a_{r}$ will be

$$
\begin{aligned}
a_{r 2} & =a_{e q 2}^{\prime}+a_{r}^{\prime \prime}=1.6149+1.1702 \\
& =2.7851 \mathrm{ohms} .
\end{aligned}
$$


In order that the deflection as a millivoltmeter for a given potential difference shall be the same at $t_{1}=20^{\circ}$ and at $t_{2}=30^{\circ}$, the resistance of the revised branch $b_{r}$ at temperature $t_{2}$, by eq 80 , must be

$$
\begin{aligned}
b_{r 2} & =\frac{2.7851 \times 8.0116}{(13.7404 \times 1.00095)-2.7851-8.0116} \\
& =7.5465 \mathrm{ohms} .
\end{aligned}
$$

The revised value of the temperature coefficient of this coil is, by eq 81 ,

$$
\beta_{\tau}=\frac{7.5465-7.3044}{10 \times 7.3044}=0.00331 /{ }^{\circ} \mathrm{C}
$$

The correctness of the revised values of $a_{1}, b_{1}, c$, and $\beta$ may now be checked. The resistance of the millivolt range at $20^{\circ} \mathrm{C}$ will be

$$
\begin{aligned}
r_{20} & =8.0116+\frac{2.7321 \times 7.3044}{2.7321+7.3044} \\
& =10.0000 \mathrm{ohms} .
\end{aligned}
$$

The current taken by this range, with an applied potential difierence of 50 millivolts, is 0.005 ampere. Of this, the part through the equivalent moving coil is $(7.3044 \times 0.005) /(2.7321+7.3044)$ equals 0.0036389 ampere. Of this, the current in the actual moving coil is $(1160.212 \times 0.0036389) /(1.564+1160.212)$ equals 0.003634 ampere.

At $30^{\circ} \mathrm{C}$ the resistance of the millivolt range will be

$$
\begin{aligned}
r_{30} & =8.0116+\frac{2.7851 \times 7.5465}{2.7851+7.5465} \\
& =10.0459 \mathrm{ohms} .
\end{aligned}
$$

The current which 50 millivolts will pass through this range is $0.050 / 10.0459$ equals $0.004,977,15$ ampere. Of this, the equivalent moving coil gets $(7.5465 \times 0.00497715) /(7.5465+2.7851)$ equals 0.00363545 ampere. Of this, the part through the actual moving coil is $(1160.21 \times 0.00363545) /(1160.21+1.617)$ equals 0.0036304 ampere. The current in the moving coil for full-scale deflection is $0.003634 / 1.001$ equals 0.0036304 - ampere. The negligible difference between this value and the preceding one is caused by rejection error in the calculations.

By a similar calculation for an intermediate temperature of $25^{\circ} \mathrm{C}$ it may be shown that for 50 millivolts applied to the millivolt range the current in the actual moving coil will have the correct value for full-scale deflection at that temperature, within 0.003 percent, that is, within 0.005 division in a deflection of 150 divisions. This defect in the compensation is negligible. For temperatures between $20^{\circ}$ and $25^{\circ}$, and between $25^{\circ}$ and $30^{\circ}$, the defect in the compensation will be smaller than 0.003 percent. 
The total damping resistance at reference temperature with the millivoltmeter terminals connected by a wire of negligible resistance is

$$
\begin{aligned}
d_{r 1} & =2.7321+\frac{7.3044 \times 8.0116}{7.3044+8.0116} \\
& =6.5529 \text { ohms. }
\end{aligned}
$$

The necessary shift in this quantity, resulting from the revision of the branches of the millivoltmeter network, is so small that its effect on the damping would not be discernible.

The remaining matter to be checked is that of the compensation of the volt ranges. The values of $p$, on the basis of which the approxi-

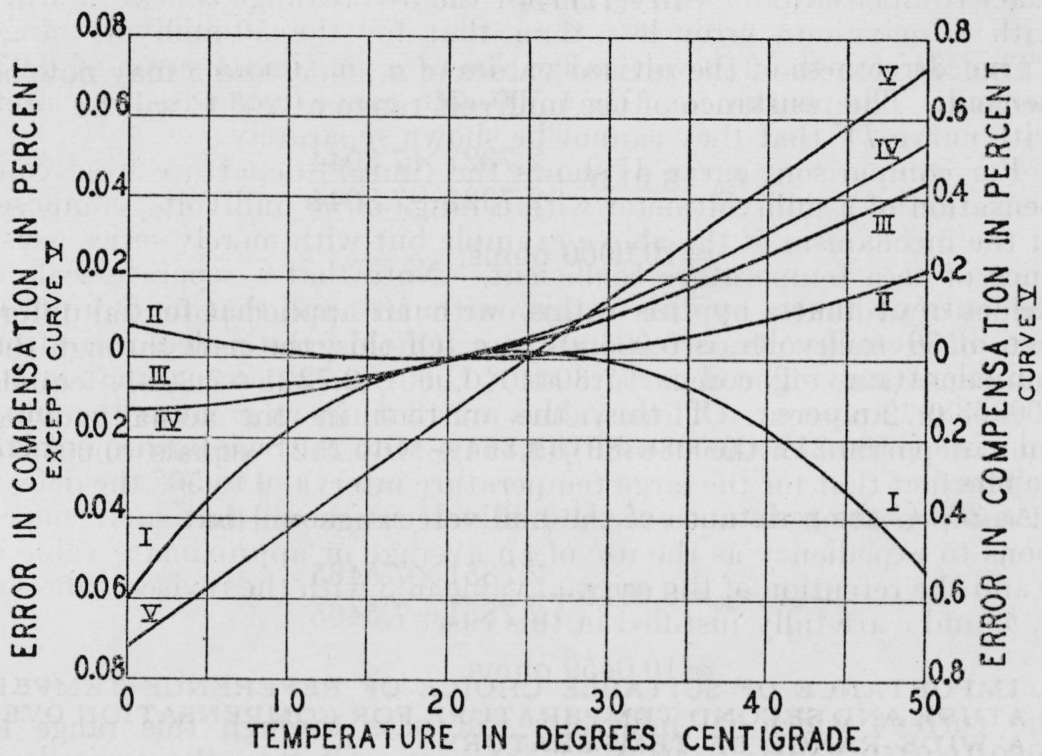

FIGURE 16.-Curves showing the departure from exact compensation for the voltmillivoltmeter of example 4 when used over a much wider range of temperature than that for which the compensation was designed.

Curves $I, I I$, and $I I I$ are for the 50-millivolt, 1.5 -volt, and 5-volt ranges, respectively. Curve $I V$ applies identically to the 150 - and 1,500-volt ranges. Curve $V$, for which a separate scale of ordinates is at the right, shows that the same mechanism, compensated merely with series resistance for the 50-millivolt range, would have departures from compensation more than 10 times as great as those for the Swinburne arrangement.

mate value $p=1$ was selected, were based on $\beta=0.00329$, and the computed revised value $\beta_{r}=0.00331$. This minute change in $\beta$ could not affect the compensation appreciably. In fact, it could not be experimentally checked by resistance measurements on the copper coil except under extremely refined conditions because it corresponds to a change of temperature of only $0.005^{\circ} \mathrm{C}$ in such a coil.

The departures from exact compensation, for the present example, are given in figure 16 for a number of the ranges. To bring out certain characteristics of the Swinburne compensation the values were computed for temperatures from 0 to $50^{\circ} \mathrm{C}$, that is, for a range extending $20^{\circ}$ below $t_{1}$ and $20^{\circ}$ above $t_{2}$. The typical curve $(I)$ for the 50 -millivolt range crosses the line of zero departure (line of exact compensation) at $20^{\circ}$ and at $30^{\circ} \mathrm{C}$, rises to a slight positive value 
which is greatest (but entirely inappreciable) near $25^{\circ}$, and falls below the line of exact compensation in approximately parabolic fashion as the temperature decreases from $20^{\circ}$ or increases from $30^{\circ}$. It is evident that if the instrument were to be used over the range 0 to $50^{\circ}$ the maximum error could be approximately halved by lifting the curve by about one-half of the error at $0^{\circ}$. This could be done readily, without altering any resistance adjustments, if the instrument has an adjustable magnetic shunt. In the given example the magnetic field would need to be increased about 0.03 percent, and the resulting maximum departure from compensation would have this value, negative for $0^{\circ}$ and plus for $25^{\circ}$.

Curve $I I$ for the 1.5 -volt range shows the smallest departure from exact compensation. Curve $I I I$ for the 5-volt range is next in order, with a maximum error less than that for the 50-millivolt range. Curve $I V$ for the 150 -volt range shows a maximum error of 0.054 percent. The curve for the 1,500-volt range coincides so closely with curve $I V$ that they cannot be shown separately.

For comparison, curve $V$ shows the (linear) departure from compensation of a millivoltmeter with a range of 50 millivolts, eomposed of the mechanism of the above example but with merely series resistance of zero temperature coefficient. Note that a separate scale of values of ordinates applies to this one curve, and that for it an ordinate of given length corresponds to a tenfold greater departure from compensation. The departure at $0^{\circ} \mathrm{C}$ is -0.72 percent, that at $50^{\circ}$ $\mathrm{C}$ is +0.72 percent. These values are 12 times as great as the maximum departure for the 50-millivolt range with the Swinburne network.

The fact that for the large temperature interval 0 to $50^{\circ}$ the defects of compensation do not exceed 0.06 percent shows that such concessions to expediency as the use of an average or approximate value of $p$ and the retention of the original value of $\beta$ with the revised values of $a, b$, and $c$ are fully justified in this case.

\section{IMPORTANCE OF SUITABLE CHOICE OF REFERENCE TEMPER- ATURE AND SECOND TEMPERATURE FOR COMPENSATION OVER A WIDE RANGE OF TEMPERATURE}

In instruments for special applications such as on airplanes, relatively large ranges of temperatures are encountered. For example. the standard upper and lower limits of temperature for the testing of airplane instruments are $+45^{\circ} \mathrm{C}$ and $-35^{\circ} \mathrm{C}$, respectively. For such wide ranges the choice of suitable values of $t_{1}$ and $t_{2}$ becomes important, as may be shown by an extension of numerical example 1 . Curve $I$ of figure 17 shows the departure from compensation of the millivoltmeter of this example for the extreme temperature range $-40^{\circ}$ to $+50^{\circ} \mathrm{C}$, computed for the original $t_{1}=20^{\circ}$ and $t_{2}=30^{\circ}$. The defect is practically all of one sign, that is, the indication of the millivoltmeter will be too low for all temperatures below $20^{\circ}$ and above $30^{\circ}$, and the maximum error $\left(\right.$ at $\left.-40^{\circ}\right)$ is 0.45 percent. It is very evident that the above reference temperatures are too close together and too far from the center of the temperature range. One way to reduce the magnitude of the maximum defect in compensation is to increase the strength of the magnetic field by about 0.22 percent, thus lifting curve $I$ to form curve $I I$. This halves the maximum error but the curve is still of undesirable form. Approximately the maximum positive defect in compensation exists over the range 
0 to $50^{\circ}$, and the change from this value to an equally large negative defect at $-40^{\circ}$ occurs at an increasing rate as the temperature decreases from $0^{\circ}$. A better choice of reference temperature and second temperature is $t_{1}=-20^{\circ} \mathrm{C}$ and $t_{2}=+30^{\circ} \mathrm{C}$. Curve III shows the resulting defect in compensation for the mechanism and the requirements of example 1 with the values of $a, b, c$, and $\beta$ revised as required by the new basic temperatures. The maximum defect in compensation is now 0.14 percent at $-40^{\circ}$. The maximum positive defect is 0.055 percent and occurs near $+5^{\circ} \mathrm{C}$. Curve $I V$ shows that by "lifting" curve $I I I$ by 0.44 percent the departure from exact compensation may be kept just within the limits \pm 0.1 percent over the whole of this large range of temperature, which is a strikingly

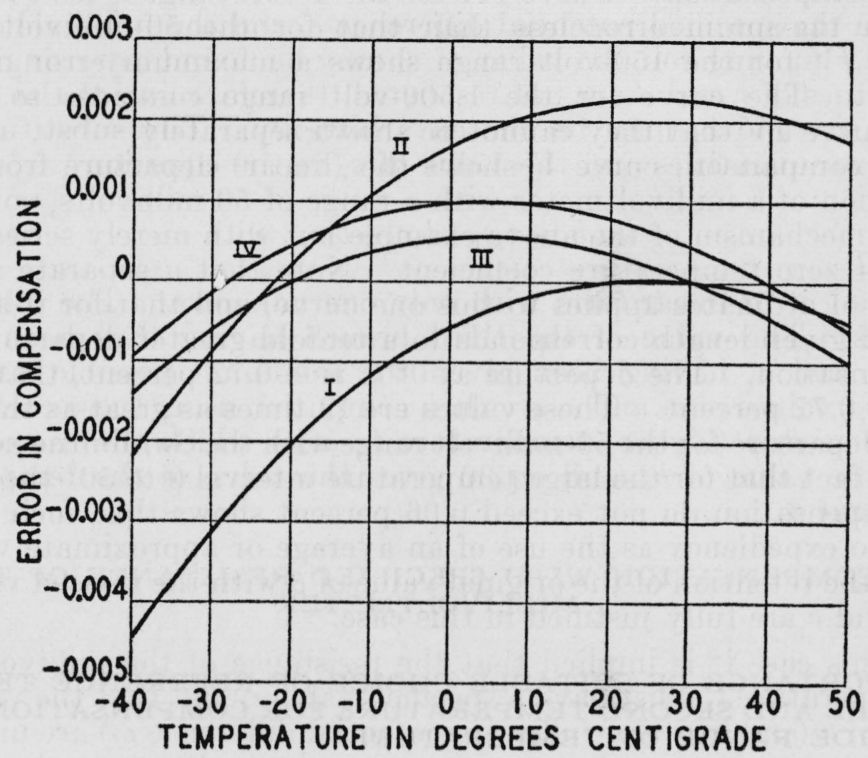

FIGURE 17.-Error in compensation of the millivoltmeter of example 1 when used over a very wide range of temperature.

Curve $I$ is for the original case of $t_{1}$ and $t_{2}=20$ and $30^{\circ} \mathrm{C}$, respectively. Curve $I I$ is equivalent to curve $I$ "lifted" to equalize the + and - errors. Curve $I I I$ is for new values $t_{1}=-20^{\circ} \mathrm{C}$ and $t_{2}=+40^{\circ} \mathrm{C}$. Curve $I V$ is curve III lifted to equalize the + and - errors. It is the curve which would apply to the case of $t_{1}=$ $-28.3^{\circ} \mathrm{C}$ and $t_{2}=+40.5^{\circ} \mathrm{C}$.

good performance. It shows that although the defect in compensation of a Swinburne-compensated millivoltmeter is necessarily a nonlinear function of temperature the defect may be kept within narrow limits by suitable choice of the reference temperature and the second temperature.

It will be noted that curve $I V$ crosses the line of zero departure at about $-28.3^{\circ}$ and $+40.5^{\circ} \mathrm{C}$. These temperatures were taken as $t_{1}$ and $t_{2}$, respectively, and the data for a curve were computed. The values of defect in compensation agreed so closely with those of curve $I V$ that it was not feasible to plot them as a separate curve.

To sum up: the mean of $t_{1}$ and $t_{2}$ should be near the center of the range of temperature to be covered, and the best values of $t_{1}$ and $t_{2}$ may be found by first assuming a pair of values, computing the 
corresponding curve, "lifting" it to make the maximum positive departure equal numerically to the maximum negative departure, and then finding the best values of $t_{1}$ and $t_{2}$ from the intersection of the lifted curve with the line of zero departure from exact compensation. The values of $a, b, c$, and $\beta$ should then be computed for these basic temperatures.

\section{COMPENSATION OF A MILLIVOLTMETER WHEN SOME QUANTITIES ARE SPECIFIED AND THE OTHERS MAY BE CHOSEN ARBITRARILY}

\section{COMPENSATION WITH SPECIFIED FULL-SCALE POTENTIAL DIFFERENCE}

From the specified potential difference $e_{f}$ and the full-scale current $i_{f_{1}}$ in the moving coil the value of $s_{1}$ may be found by using eq 15 . The values of $r$ and $d$ are not restricted, therefore two of the quantities $a_{1}, b_{1}$, and $c_{1}$ may be chosen arbitrarily. The substitution of these two quantities and the value of $s_{1}$ in the equation

$$
a_{1} b_{1}+a_{1} c_{1}+b_{1} c_{1}-b_{1} s_{1}=0
$$

will leave it in linear form with only one unknown. The solution is obvious. The value of the third branch having thus been found, and $a_{1}$ and $c_{1}$ having been given the minimum possible values of $\alpha$ and $\gamma$, values of $a_{2}$ and $c_{2}$ are then computed, using these coefficients for the second (higher) temperature $t_{2}$, after which the use of eq 29 gives the value of $b_{2}$, and eq 30 gives the value of the temperature coefficient $\beta$.

\section{COMPENSATION WITH SPECIFIED RESISTANCE OF THE MILLIVOLTMETER}

In this case it is implied that the resistance of the millivoltmeter at temperature $t_{1}$ must have a specified value $r_{1}$ and that the values of $d$ and of $s$ (and hence of full-scale potential difference $e_{f}$ ) are unimportant. Again two of the quantities, $a_{1}, b_{1}$, and $c_{1}$ may be chosen arbitrarily. They are to be substituted, with the value of $r_{1}$, in eq 19, namely,

$$
a_{1} b_{1}+a_{1} c_{1}+b_{1} c_{1}-a_{1} r_{1}-b_{1} r_{1}=0
$$

and the resulting linear equation is then to be solved for the third unknown. The procedure for finding the values of $b_{2}$ and $\beta$ is the same as that given for the preceding case.

\section{COMPENSATION WITH SPECIFIED TOTAL DAMPING RESISTANCE}

In the case it is implied that the total damping resistance at temperature $t_{1}$ must have a specified value $d_{1}$ and that the values of $r$ and $s$ are unimportant. As in the two preceding cases, any two of the values of $a_{1}, b_{1}$, and $c_{1}$ are chosen. With the prescribed value of $d_{1}$ they are substituted in eq 21 , namely,

$$
a_{1} b_{1}+a_{1} c_{1}+b_{1} c_{1}-b_{1} d_{1}-c_{1} d_{1}=0
$$


and the resulting linear equation is then solved for the remaining unknown. The procedure for finding $b_{2}$ and $\beta$ is the same as in the two preceding cases.

4. COMPENSATION WITH SPECIFIED FULL-SCALE POTENTIAL DIFFERENCE AND SPECIFIED RESISTANCE OF THE MILLIVOLTMETER

In this case only one of the values of $a_{1}, b_{1}$, and $c_{1}$ may be chosen arbitrarily. The equations relating to this case are

$$
\begin{array}{r}
a_{1} b_{1}+a_{1} c_{1}+b_{1} c_{1}-b_{1} s_{1}=0 \\
a_{1} b_{1}+a_{1} c_{1}+b_{1} c_{1}-a_{1} r_{1}-b_{1} r_{1}=0
\end{array}
$$

from which it follows that

$$
\begin{aligned}
a_{1} r_{1}+b_{1} r_{1}-b_{1} s_{1} & =0 \\
b_{1} & =\frac{a_{1} r_{1}}{s_{1}-r_{1}} \\
a_{1} & =\frac{b_{1}\left(s_{1}-r_{1}\right)}{r_{1}}
\end{aligned}
$$

If $a_{1}$ has been arbitrarily chosen, the value of $b_{1}$ is given explicitly by eq 83 , and $c_{1}$ is found by using a relation derived from eq 17 and 83, namely,

$$
c_{1}=\frac{r_{1} s_{1}-a_{1} r_{1}}{s_{1}}
$$

If $b_{1}$ has been chosen, the value of $a_{1}$ is given directly by eq 84 and $c_{1}$ by eq 85 . If $c_{1}$ has been chosen, the value of $a_{1}$ may be found by using the formula, derived from eq 85 ,

$$
a_{1}=\frac{s_{1}\left(r_{1}-c_{1}\right)}{r_{1}}
$$

after which the value of $a_{1}$ is substituted in eq 83 to get the value of $b_{1}$. The values of $b_{2}$ and $\beta$ are then computed as in the preceding cases.

\section{COMPENSATION WITH SPECIFIED FULL-SCALE POTENTIAL} DIFFERENCE AND SPECIFIED TOTAL DAMPING RESISTANCE

Here also only one of the quantities $a_{1}, b_{1}$, and $c_{1}$ may be chosen arbitrarily. The appropriate equations are

$$
\begin{aligned}
& a_{1} b_{1}+a_{1} c_{1}+b_{1} c_{1}-b_{1} s_{1}=0 \\
& a_{1} b_{1}+a_{1} c_{1}+b_{1} c_{1}-b_{1} d_{1}-c_{1} d_{1}=0
\end{aligned}
$$


from which it follows that

$$
\begin{aligned}
b_{1} d_{1}+c_{1} d_{1}-b_{1} s_{1} & =0 \\
b_{1} & =\frac{c_{1} d_{1}}{s_{1}-d_{1}} \\
c_{1} & =\frac{b_{1}\left(s_{1}-d_{1}\right)}{d_{1}}
\end{aligned}
$$

If $b_{1}$ is the arbitrarily chosen quantity, the value of $c_{1}$ is given directly by eq 89 , and if $c_{1}$ is given, $b_{1}$ is found by using eq 88 . In either case the value of $a_{1}$ is found by the use of a relation derived from eq 17 and 88 , namely,

$$
a_{1}=\frac{d_{1}\left(s_{1}-c_{1}\right)}{s_{1}}
$$

If $a_{1}$ is chosen, $c_{1}$ may be found from a relation derived from eq 90 , namely,

$$
c_{1}=\frac{s_{1}\left(d_{1}-a_{1}\right)}{d_{1}}
$$

after which the value of $b_{1}$ is to be found by the use of eq 88 . The values of $b_{2}$ and $\beta$ are then to be computed as in the preceding cases.

\section{COMPENSATION WITH SPECIFIED RESISTANCE OF THE MILLI- VOLTMETER AND SPECIFIED TOTAL DAMPING RESISTANCE}

The basic equations applying to this case are

$$
\begin{aligned}
& a_{1} b_{1}+a_{1} c_{1}+b_{1} c_{1}-a_{1} r_{1}-b_{1} r_{1}=0 \\
& a_{1} b_{1}+a_{1} c_{1}+b_{1} c_{1}-b_{1} d_{1}-c_{1} d_{1}=0
\end{aligned}
$$

Any one (but only one) of the quantities $a_{1}, b_{1}$, and $c_{1}$ may be chosen arbitrarily, after which eq 19 and 21 may be solved for the other two. The solution yields two pairs of roots. According to the relative magnitude of the arbitrarily chosen quantity, one pair or both pairs may lead to physically possible values of resistance or to negative or imaginary values which cannot be realized. When both pairs of roots lead to positive real values of resistance there may be a large difference in matters of performance in the two cases, such as the full-scale potential difference or the fractional part of the current which is bypassed around the moving coil and produces no torque. There are three cases.

Case 1.-Let $a_{1}$ be chosen arbitrarily. The solution of eq 19 for $b_{1}$ is

$$
b_{1}=\frac{a_{1}\left(r_{1}-c_{1}\right)}{a_{1}+c_{1}-r_{1}}
$$


The substitution of this value of $b_{1}$ in eq 21 gives a quadratic equation in $c_{1}$ of which the solution is

$$
c_{1}=\frac{r_{1} \pm\left[r_{1}^{2}-4 a_{1} r_{1}\left(d_{1}-a_{1}\right) / d_{1}\right]^{\frac{2}{2}}}{2}
$$

Each of the two values of $c_{1}$, substituted in eq 92 with the chosen value of $a_{1}$, gives a corresponding value of $b_{1}$. Note that the value of $b_{1}$ corresponding to one of the values of $c_{1}$ is not applicable with the other value of $c_{1}$.

Case 2.-Let $b_{1}$ be chosen arbitrarily. The solution of eq 19 for $a_{1}$ is

$$
a_{1}=\frac{b_{1}\left(r_{1}-c_{1}\right)}{b_{1}+c_{1}-r_{1}}
$$

The substitution of this value of $a_{1}$ in eq 21 gives a quadratic equation in $c_{1}$ of which the solution is

$$
c_{1}=\frac{r_{1}-2 b_{1} \pm\left[\left(r_{1}-2 b_{1}\right)^{2}-4 b_{1}\left(b_{1}-r_{1}-b_{1} r_{1} / d_{1}\right)\right]^{\frac{1}{2}}}{2}
$$

Each value of $c_{1}$, substituted in eq 94 with the chosen value of $b_{1}$, gives a corresponding value of $a_{1}$. Each value of $a_{1}$ is applicable only with the value of $c_{1}$ which gives rise to it.

Case 3.-Let $c_{1}$ be chosen arbitrarily. The quadratic equation of case 1 may be rearranged with $a_{1}$ as the unknown. The solution is

$$
a_{1}=\frac{d_{1} \pm\left[d_{1}^{2}-4 c_{1} d_{1}\left(r_{1}-c_{1}\right) / r_{1}\right]^{\frac{1}{2}}}{2}
$$

Each of these two roots, substituted in eq 92 with the chosen value of $c_{1}$, gives the corresponding value of $b_{1}$.

In each of these three cases the solution is to be completed by finding the minimum possible values of $\alpha$ and $\gamma$, computing from them values of $a_{2}$ and $b_{2}$ for the desired higher temperature $t_{2}$, determining $b_{2}$ by eq 29 , and finally determining $\beta$ by eq 30 . The minimum possible values of $\alpha$ and $\gamma$ are obtained by making the coil $a^{\prime \prime}$ and all (or as much as possible) of the $c$ branch of manganin.

\section{EXPERIMENTAL PROCEDURES FOR ROUTINE COMPENSATION OF INSTRUMENTS OF A GIVEN TYPE}

\section{NECESSITY FOR AND PREPARATIONS FOR THE EXPERIMENTAL PROCEDURES}

In the routine manufacture of millivoltmeters of a given type to meet identical requirements it is an economic necessity to have simple and rapid methods. Such methods are proposed in outline here in the hope that they may at least suggest feasible procedures to those who (unlike the author) are in direct touch with the problems of instrument manufacture.

If each millivoltmeter were to be compensated individually in accordance with the appropriate formulas of this paper, the following data would have to be determined for it experimentally: resistance $a^{\prime}$ of the moving coil and current $i_{f}$ for full-scale deflection at two 
accurately known temperatures, and the total resistance $d$ for the kind of damping desired. To determine the values of $a^{\prime \prime}, b, c$, and $\beta$ would require calculations for each instrument.

In preparation for the proposed more practical and expeditious experimental procedures the above detailed process would be carried out for a sufficient number of instruments to obtain good average values of $a, b$, and $c$. Thereafter, each millivoltmeter mechanism would be subjected to certain tests in a controlled-temperature enclosure having a window through which the indication could be accurately observed. Such an enclosure is indicated diagrammati-

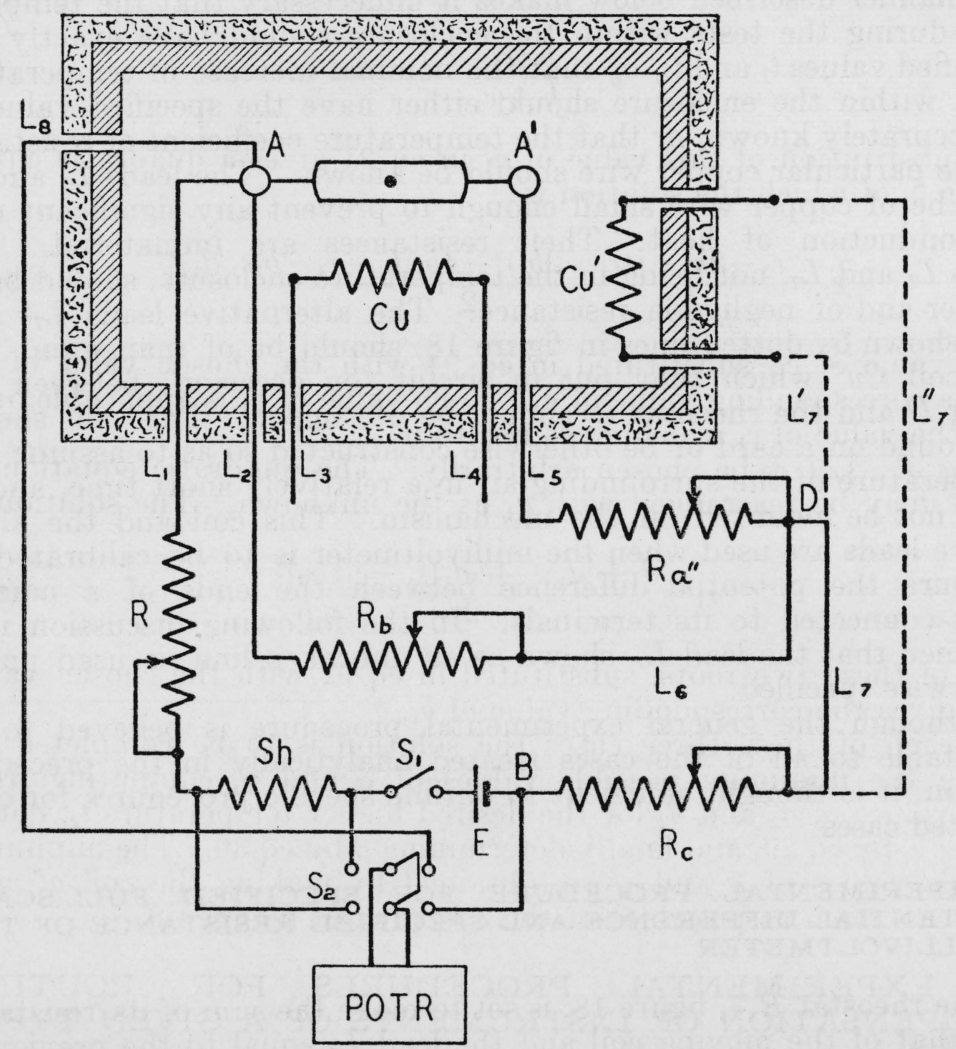

Figure 18.-Experimental method of millivoltmeter compensation.

The mechanism and copper coils $C u$ and $C u^{\prime}$ are in a controlled-temperature enclosure. Manganin rheostats $R_{a}, R_{b}$, and $R_{\mathrm{e}}$ serve as temporary $a^{n}, b$, and $c$ coils, respectively. A cell $E$ supplies a current which can be regulated by the rheostat $R$ and measured by the potentiometer and shunt $S h$.

cally in figure 18. Manganin leads $L_{2}$ and $L_{5}$ are brought out from the ends $A$ and $A^{\prime}$ of the moving coil ${ }^{23}$ and similar leads $L_{3}$ and $L_{4}$ are brought out from the ends of a copper coil $C u$. Three manganin rheostats $R_{a^{*}}, R_{b}$, and $R_{c}$ are used as temporary $a^{\prime \prime}, b$, and $c$ coils, respectively. It is necessary that these rheostats be capable of fine adjustment, say to $0.01 \mathrm{ohm}$ or finer. Ordinary precision rheostats do not usually have such small steps. The use of the Waidner-

\footnotetext{
${ }_{23}$ That is, from the outer ends of the springs which conduct the current to and from the moving coil.
} 
Wolff ${ }^{24}$ adjustable resistance element makes such steps, and even much finer ones, entirely feasible. Rheostats composed of such elements, adjustable in steps of say $0.001 \mathrm{ohm}$, are essential for the rapid and accurate performance of the necessary tests. The leads $L_{2}$ to $L_{5}$ inclusive are preferably adjusted to convenient round values of resistance which have to be taken into account. ${ }^{25}$ The copper coil $C u$ is wound on a metal spool which is mounted in close thermal proximity to the moving coil, as it will be in the final assembly of the instrument, but it is given a resistance say 10 percent larger than the value which experience indicates will be finally required. Its use in the manner described below makes it unnecessary that the temperature during the tests within the enclosure should have exactly the specified values $t_{1}$ and $t_{2}$, or that the nominal increase of temperature $t_{2}-t_{1}$ within the enclosure should either have the specified value or be accurately known, or that the temperature coefficient of resistance of the particular copper wire should be known. The leads $L_{1}$ and $L_{8}$ may be of copper wire small enough to prevent any significant rate of conduction of heat. Their resistances are immaterial. The leads $L_{6}$ and $L_{7}$, not being in the temperature enclosure, should be of copper and of negligible resistance. The alternative leads $L_{7}{ }^{\prime}$ and $L_{7}^{\prime \prime}$, shown by dotted lines in figure 18 , should be of manganin, and the coil $C u^{\prime}$ which they put in circuit (on occasion) between the point $D$ and the rheostat $R_{c}$ should be of copper. This coil should be wound on a card or be otherwise constructed so as to assume the temperature of the surrounding air in a relatively short time, and it need not be mounted on the mechanism. This coil and the alternative leads are used when the millivoltmeter is to be calibrated to measure the potential difference between the ends of a pair of leads connected to its terminals. In the following discussion it is assumed that the lead $L_{7}$, shown as an unbroken line, is used unless otherwise specified.

Although the general experimental procedure is believed to be adaptable to all of the cases treated analytically in the preceding section, it is thought sufficient to outline specific procedures for only selected cases.

\section{EXPERIMENTAL PROCEDURE FOR SPECIFIED FULL-SCALE POTENTIAL DIFFERENCE AND SPECIFIED RESISTANCE OF THE MILLIVOLTMETER}

The rheostat $R_{\mathrm{a}}$, figure 18 , is set to make the sum of its resistance and that of the moving coil and the lead $L_{5}$ equal to the previously determined average value of $a_{1}$. The temperature within the enclosure is held at or close to the reference temperature $t_{1}$ until the temperature within the millivoltmeter mechanism is constant, as shown by the constancy of the resistance of the copper coil $\mathrm{Cu}$. The value of this resistance is recorded. The switch $S_{1}$ is then closed and the rheostat $R$ is adjusted until the current measured by the potentiometer and the shunt $S h$ has the value $e_{f} / r$, where $e_{f}$ and $r$ are the specified fullscale potential difference and the specified resistance of the millivolt-

24 J. Research, NBS 15, 477, (1935) RP842.

${ }^{25}$ If $L_{2}$ to $L_{5}$ were of copper, subsidiary measurements would have to be made on a pair of similar "dummy" leads extending into the enclosure and having their inner ends joined together. It would not, answer the purpose to make these leads of heavy copper wire to make the resistance negligible, because such leads would conduct too much heat. - Manganin has only one-twentieth of the thermal conductivity of copper. 
meter. The rheostat $R_{b}$ is then adjusted to give full-scale deflection, the current being kept constant meanwhile by readjustment of $R$. The resistance of $R_{b}$ is then recorded; with the resistances of $L_{2}$ and $L_{6}$ added, it gives the value of resistance $b_{1}$ which the final $b$ coil must have at this temperature (approximately $t_{1}$ ). The value of the resistance $R_{c}$ up to this time is immaterial. The potentiometer is then connected to measure the potential difference between the points $A$ and $B$, and this potential difference is regulated by the rheostat $R$ while the rheostat $R_{c}$ is adjusted until the specified full-scale potential difference produces full-scale deflection. If the millivoltmeter is to indicate the difference of potential between its own terminals, the resistance of $R_{c}$ plus that of $L_{7}$ equals the resistance which the final $c$ coil should have at reference temperature. If the millivoltmeter is to indicate the difference of potential between the ends of a pair of copper leads attached to its terminals, the procedure just outlined would differ only in that the lead $L_{7}$ would be removed and its place taken by the manganin leads $L_{7}^{\prime}$ and $L_{7}^{\prime \prime}$ and the coil $C u^{\prime}$, this coil having a resistance equal to that of the pair of leads. In this case, the sum of the resistances $R_{c}, L_{7}{ }^{\prime}$, and $L_{7}^{\prime \prime}$ equals the resistance to which the final manganin $c$ coil should be adjusted.

The determinations at approximately reference temperature $t_{1}$ having been completed, the temperature within the enclosure is then raised to approximately $t_{2}$ and held until the resistance of the coil $C u$ becomes constant. The value of this resistance is recorded. The switch $S_{1}$ is then closed, $R_{a^{\prime \prime}}$ and $R_{c}$ are left undisturbed, and the resistance of $R_{b}$ is increased to make full-scale deflection again correspond to the specified potential difference ${ }^{26}$ between $A$ and $B$. The increment $\Delta b$ in the resistance of $R_{b}$ is the amount by which the copper coil, which is to form part of the final $b$ branch, must increase for the given increase in temperature. Because the resistance of the coil $C u$ was made a little larger than necessary, its observed increase in resistance $\Delta C u$ will be somewhat larger than $\Delta b$. The resistance of the coil $C u$ must be reduced so that the portion remaining, if it had been in the enclosure, would have shown a change in resistance equal to $\Delta b$; that is, its resistance must be made $\Delta b / \Delta C u$ times its original value. The temperature at which this relative reduction in resistance is made is immaterial. ${ }^{27}$ The coil is then to be remounted within the mechanism, one of its terminals is to be connected to the point $A$, and the manganin coils $a^{\prime \prime}$ and $c$ are to be mounted and connected, all as shown in figure 1 , but with the $b$ branch as yet incomplete. A suitable finely adjustable rheostat, for example, $R_{a}$ " of figure 18 , is used to close the gap in the $b$ branch temporarily, and is adjusted until the specified potential difference $e_{f}$ gives full-scale deflection at approximately reference temperature. ${ }^{28} \mathrm{~A}$ manganin coil having a

\footnotetext{
${ }_{26}$ A slight shift of zero is sometimes caused by raising the temperature of the mechanism. When this occurs, and the zero adjuster is inaccessible, allowance should be made for the shift so that the net angular deflection is the same at $t_{2}$ and $t_{1}$.

${ }^{27}$ It is difficult to adjust a copper coil accurately. The author places the coil, which is wound on a brass spool, on a massive metal block which rests on the bottom of a thick-walled cast-aluminum vessel having a cover of the same material. Manganin leads of known resistance are brought out from the ends of the coil to a bridge. One junction of a thermocouple is clamped to the massive metal block and the other is in an ice bath. The aluminum vessel is surrounded by heat-insulating material contained in a box. Suitable means are provided for holding the temperature of the vessel at desired values.

When the resistance of the coil at a definite temperature has been measured, the coil is removed and ad. justed by measuring with the bridge the resistance of the small margin to be removed. A given relative error in this measurement affects the resistance of the finished coil to a much smaller extent than it would if error in this measurement affects the resistance of the finished coil to a much smaller

${ }_{28} \mathrm{It}$ is not necessary that this test should be made at exactly the first temperature (approximately $t_{1}$ ) used in the test within the enclosure, nor that the millivoltmeter should be in the enclosure. The test might be made equally well at or near the second temperature used in the test within the enclosure.
} 
resistance equal to that to which this rheostat was adjusted during this test, plus the resistance of the necessary connecting leads used, is then mounted in the millivoltmeter and connected to complete the $b$ branch and consequently the electrical network of the millivoltmeter.

\section{EXPERIMENTAL PROCEDURE FOR SPECIFIED FULL-SCALE POTENTIAL DIFFERENCE AND SPECIFIED TOTAL DAMPING RESISTANCE}

In this case, at reference temperature, $R_{a^{\prime \prime}}$ and $R_{b}$ are set to make the resistances of the corresponding arms equal to the predetermined average values. The potential difference between the points $A$ and $B$ is then brought to the specified full-scale value while $R_{c}$ is adjusted to give full-scale deflection. The switch $S_{1}$ is then opened, $A$ and $B$ are joined ${ }^{29}$ by a wire of negligible resistance, the lead $L_{5}$ is disconnected from $R_{a^{\prime \prime}}$ and a bridge or an ohmmeter is connected in the gap so formed to measure the actual value of total damping resistance. If this resistance is too large, for example, the resistance of $R_{c}$ is reduced by a small amount and $R_{b}$ is reduced until the specified potential difference again produces full-scale deflection. The measurement of total damping resistance $d$ is then repeated. After a few trials, with values of $d$ recorded as a function of $R_{c}$, interpolation will give with sufficient accuracy the value of $c$ to produce the desired value of $d$.

The rest of the procedure, at the higher temperature $t_{2}$, is the same as in the preceding section.

It is assumed in the above method that the mechanism is received for this test with a specified value of $d$ which has been experimentally determined for it. If damping caused by pivot and air friction be neglected, the value of $d$, in instruments nominally identical, will vary directly as the square of the magnetic flux density in the air gap and inversely, as the square root of the spring strength. In the next section the variation in $d$ resulting from manufacturing variations in the strength of the magnets will be taken into account.

\section{EXPERIMENTAL PROCEDURE FOR SPECIFIED FULL-SCALE POTENTIAL DIFFERENCE, SPECIFIED RESISTANCE OF THE MILLIVOLTMETER, AND SPECIFIED TOTAL DAMPING RESIST - ANCE OF AN INSTRUMENT OF NORMAL STRENGTH OF MAGNET}

It is assumed in this case that each millivoltmeter mechanism is received for test with specified values of $e_{f}$ and $r$; that the strength of the magnets will vary from the average value and that no magnetic shunt is used to bring the field strength to the standard value; that the variation in the strength of the springs, among different instruments, is small enough to be disregarded; and that the damping is to be the same as that of an instrument of normal field strength having a total damping resistance $d$. A given relative variation in field strength of individual mechanisms will cause the same relative variation in the sensitivity resistance $s$, and for a given value of $s$ there is a unique set of values of $a, b$, and $c$. Such sets of values may be computed, by means of eq 22 to 24 , for values of $s$ over a suffi-

20 To make the point $A$ accessible for this purpose, the greater part of the lead $L_{8}$ may be made of copper wire large enough to make its resistance negligible, and only the short piece which enters the enclosure may be of finer wire. 
cient range to take care of manufacturing variations and with values of $d$ which vary as the square of $s$. Values computed on this basis

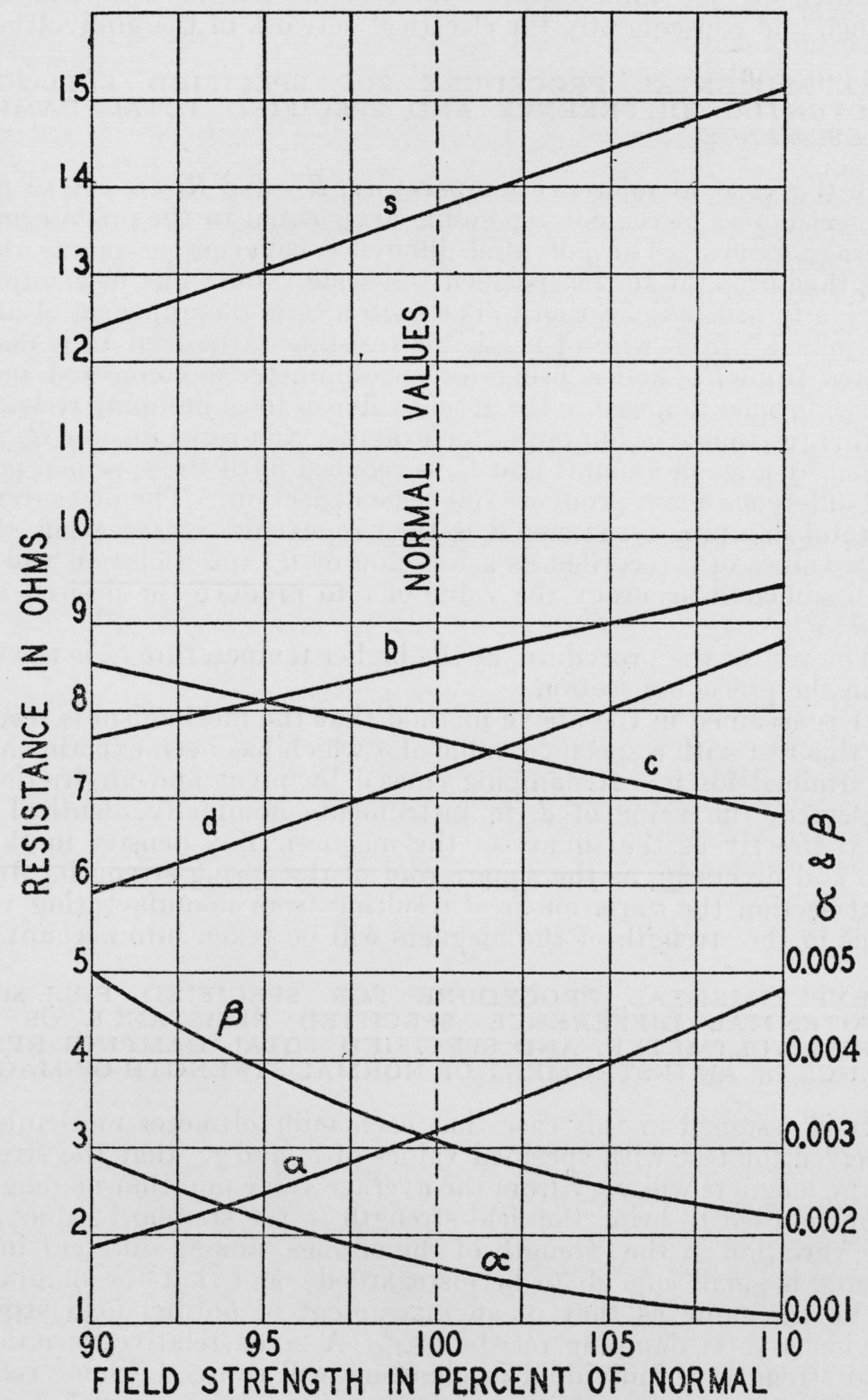

Figure 19.-Curves showing the manner in which the resistances $a, b$, $c$, and $d$ and the temperature coefficients $a$ and $\beta$ must vary to maintain specified values of $e_{f}$ and $r$ and a specified degree of damping for a range of values of strength of magnetic field between 0.9 times normal value and 1.1 times normal value.

for the millivoltmeter mechanism of example 1 are shown in figure 19. It may be seen that if the sensitivity of a given mechanism is 
higher than normal (that is, the current in the moving coil for fullscale deflection is less than normal) it is necessary to increase $a$ and $b$ and decrease $c$. The converse statements apply when the sensitivity resistance is below the normal value.

The mechanism under test having been in the enclosure (fig. 18) at approximately reference temperature $t_{1}$ until the resistance of the coil $C u$ is constant, the resistance of $R_{b}$ is made infinite, that of $R_{a^{\prime \prime}}$ is made zero, the switch $S_{1}$ is closed, and $R$ and $R_{\mathrm{c}}$ are varied until the potential difference between $A$ and $B$ has the specified value and the pointer is deflected to the full-scale mark. The switch $S_{1}$ is then opened and the resistance from $A$ to $B$ is measured. With this experimentally determined value of $s$ the curves of figure 19 are used to find the appropriate values of $a, b$, and $c . \quad R_{a^{\prime \prime}}, R_{b}$, and $R_{c}$ are then set to give the corresponding branches these values. Full-scale potential difference is then applied between $A$ and $B$ as a check, after which the resistance $r$ between these points may be measured. The total damping resistance $d$ may be checked by short-circuiting the instrument across the terminals $A$ and $B$, opening the connection between $L_{5}$ and $R_{a^{\prime \prime}}$, and inserting an ohmmeter or a bridge in the gap so formed.

The rest of the procedure, at the higher temperature $t_{2}$, is the same as in the two preceding sections.

\section{EXPERIMENTAL PROCEDURE FOR LOCATING THE VOLTMETER TAP POINT}

It is suggested, on the basis of the author's limited experience, that it will probably be sufficient to determine the location of the voltmeter tap point for a moderate number of instruments of a given model, and thereafter to use the average location of this point for all such instruments.

The determination of the voltmeter tap point is to be made with the mechanism in the controlled-temperature enclosure after the values of $a_{1}, b_{1}$, and $c_{1}$ have been found for the millivolt range. The connections are as shown in figure 20 . The rheostat $R_{c}$ is connected in series with $R_{a^{\prime \prime}}$ and one terminal of the supply cell $E$ is connected to the junction $T$ of $R_{a^{\prime \prime}}$ and $R_{c}$. This junction is thus a tap point on the $a^{\prime \prime}$ branch of the network, and the procedure is to vary the resistance in these two rheostats while the sum of their resistances is kept constant at the value which $R_{a^{\prime \prime}}$ had in the test of the given mechanism as a millivoltmeter. This procedure is equivalent to sliding the point $T$ along the $a^{\prime \prime}$ part of the $a$ branch, and in fact, a slide wire could be used for this purpose if means could be provided for conveniently bringing its entire resistance to the value which $R_{a^{\prime \prime}}$ had when the mechanism was tested as a millivoltmeter.

To avoid the taking of unnecessary observations the average location of the tap point in similar instruments previously tested should be known, and the rheostats $R_{a^{\prime \prime}}$ and $R_{c}$ should be set initially to reproduce this condition. With the mechanism at or near reference temperature the switch $S$ is closed and the rheostat $R$ is adjusted to give full-scale deflection of the mechanism under test. The magnitude of the current $I_{1}$ is then recorded, the resistance of $R_{a^{\prime \prime}}$ is increased and that of $R_{c}$ is decreased by the same amount to produce the effect of shifting the tap point $T$ by say 5 percent of $a^{\prime \prime}$, and the $89799-36-5$ 
new value of $I$ is recorded. The process is repeated after $T$ has been set to give a 10-percent shift in the same direction and then shifts of 5 percent and 10 percent in the opposite direction from the initial position. The temperature of the mechanism is then raised to approximately $t_{2}$ and the resistance of $R_{b}$ is then raised to the value appropriate for this temperature, as shown by the previous test for compensation as a millivoltmeter, after which the values of the current $I$ are measured for the five positions of $T$ previously used. The five values $I_{1}$ at temperature $t_{1}$ are plotted in a curve as a function of $p a^{\prime \prime}$, that is, of the resistance of $R_{c}$, and the five values $I_{2}$ at temperature $t_{2}$ are plotted to the same coordinates as a second curve. The

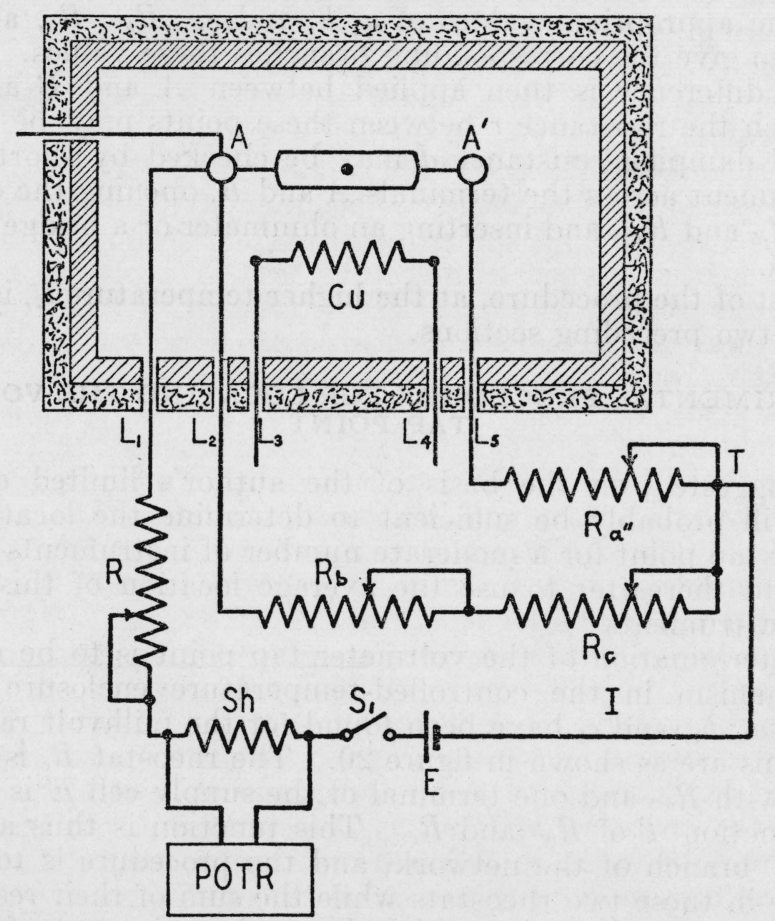

FigdRe 20.-Experimental method of locating the voltmeter tap point.

The mechanism and a copper coil $C u$ are in a controlled-temperature enclosure. The manganin rheostat $R_{b}$ serves as a temporary $b$ branch while $R_{a}$ " and $R_{c}$ in series serve as a temporary $a^{\prime \prime}$ coil. By varying $R_{a}$ and $R_{\mathrm{c}}$ " while keeping their sum constant the effect of moving the tap point $T$ along the $a^{*}$ coil is obtained.

abscissa of the point of intersection of these two curves is the value which $p a^{\prime \prime}$ should have for volt ranges in which the proportion of copper to manganin is so small that the current for a constant applied voltage may be regarded as constant over the working range of temperature. It will be seen from the values of $n$ and $p$ for example 2, p. 527, that $p$ for that case changes only 3 percent for volt ranges from 1.5 to 1,500 volts. Furthermore, a degree of temperature compensation adequate for practical purposes when the limited accuracy of reading the deflection is considered, may be obtained with only a moderately accurate value of $p$. For instance, in example 3 , p. 529, in which $\mathrm{p}=0.9965$ for $n=\infty$, the use of $p=0.75$ causes a defect in 
compensation of only 0.1 percent when the temperature is increased from 20 to $30^{\circ} \mathrm{C}$.

\section{EXPERIMENTAL PROCEDURE FOR DETERMINING THE EFFECT ON THE COMPENSATION OF MANUFACTURING VARIATIONS OF MILLIVOLTMETER CONSTANTS FROM THEIR AVERAGE VALUES}

After a number of millivoltmeters have been compensated by the process of accurately measuring their constants and computing appropriate values, it would save much expense thereafter if subsequent instruments could be given the values of $a, b, c$, and $\beta$ which had been found to apply to the average instrument. It is desirable, before doing this, to ascertain the effect on the compensation of the manufacturing variations in certain constants of the instruments. For simplicity, let it be assumed that each mechanism in question. has a magnetic shunt by means of which $s$ can be brought to the standard value. The constants which will vary from one instrument to another, and on which a sufficient number of values should be observed, are $a_{1}{ }^{\prime} \alpha^{\prime}, b_{1} \beta$, and $\delta$. The quantity $a_{1}{ }^{\prime} \alpha^{\prime}$ is the increase in resistance, in ohms, of the moving coil and springs for an increase of $1^{\circ}$ above the reference temperature, and a knowledge of its value makes it unnecessary to know its components $a_{1}{ }^{\prime}$ and $\alpha^{\prime}$, both of which may vary in opposite directions without affecting the performance, if their product remains unchanged.

'The test may be made for convenience in the temperature-controlled enclosure of figure 18. With the rheostats $R_{a^{\prime \prime}}, R_{b}$, and $R_{e}$ set to give the standard values, $S_{1}$ closed and $R$ adjusted to give fullscale deflection, $R_{a^{\prime \prime}}$ is changed by the amount of $\left(t_{2}-t_{1}\right) \Delta a_{1}{ }^{\prime} \alpha^{\prime}$, where $t_{2}-t_{1}$ is the standard temperature interval and $\Delta a_{1}^{\prime} \alpha^{\prime}$ is the largest observed departure in $a_{1}^{\prime} \alpha^{\prime}$ from its average value. The resulting displacement of the pointer from the full-scale mark will be the error of compensation which would be caused by this maximum value of $\Delta a_{1}^{\prime} \alpha^{\prime}$ if the instrument were to be equipped with coils of the standard values. Similarly, if it is known that in a number of copper $b$ coils, the resistances of which to produce compensation have been determined experimentally or by computation, the maximum variation from the mean value of $\Delta b$ has a given value, the effect of this variation may be found in the same manner as that of $\Delta a_{1}{ }^{\prime} \alpha^{\prime}$. The effect of the maximum variation $\Delta \delta$ of the coefficient $\delta$ from its average value needs no experiment and is simply $\left(t_{2}-t_{1}\right) \Delta \delta$. Finally, the greatest possible defect in the compensation, under the most unfavorable conditions, may be had by adding the observed effects of the three variations.

Washington, JUne 12, 1936. 